NOTICE: this is the author's version of a work that was accepted for publication in Geochimica et Cosmochimica Acta. Changes resulting from the publishing process, such as peer review, editing, corrections, structural formatting, and other quality control mechanisms may not be reflected in this document. Changes may have been made to this work since it was submitted for publication. A definitive version was subsequently published in Geochimica et Cosmochimica Acta, Vol. 122 (2013). DOI: 10.1016/j.gca.2013.08.020 


\title{
Estimation and application of the thermodynamic properties of aqueous phenanthrene and isomers of methylphenanthrene at high temperature
}

\author{
Jeffrey M. Dick ${ }^{\mathrm{a}, \mathrm{b}, *}$, Katy A. Evans ${ }^{\mathrm{b}}$, Alex I. Holman ${ }^{\mathrm{a}}$, Caroline M. B. Jaraula ${ }^{\mathrm{a}}$, Kliti Grice ${ }^{\mathrm{a}}$ \\ ${ }^{a}$ Department of Chemistry, Curtin University, GPO Box U1987, Perth, WA 6845, Australia \\ ${ }^{b}$ Department of Applied Geology, Curtin University, GPO Box U1987, Perth, WA 6845, Australia
}

\begin{abstract}
Estimates of standard molal Gibbs energy $\left(\Delta G_{f}^{\circ}\right)$ and enthalpy $\left(\Delta H_{f}^{\circ}\right)$ of formation, entropy $\left(S^{\circ}\right)$, heat capacity $\left(C_{P}^{\circ}\right)$ and volume $\left(V^{\circ}\right)$ at $25^{\circ} \mathrm{C}$ and 1 bar of aqueous phenanthrene (P) and 1-, 2-, 3-, 4- and 9methylphenanthrene (1-MP, 2-MP, 3-MP, 4-MP, 9-MP) were made by combining reported standard-state properties of the crystalline compounds, solubilities and enthalpies of phenanthrene and 1-MP, and relative Gibbs energies, enthalpies and entropies of aqueous MP isomers from published quantum chemical simulations. The calculated properties are consistent with greater stabilities of the $\beta$ isomers (2-MP and 3 -MP) relative to the $\alpha$ isomers (1-MP and 9-MP) at $25^{\circ} \mathrm{C}$. However, the metastable equilibrium values of the abundance ratios 2-MP/1-MP (MPR) and (2-MP + 3-MP)/(1-MP + 9-MP) (MPI-3) decrease with temperature, becoming $<1$ at $\sim 375-455^{\circ} \mathrm{C}$. The thermodynamic model is consistent with observations of reversals of these organic maturity parameters at high temperature in hydrothermal and metamorphic settings. Application of the model to data reported for the Paleoproterozoic Here's Your Chance (HYC) $\mathrm{Pb}-\mathrm{Zn}-\mathrm{Ag}$ ore deposit (McArthur River, Northern Territory, Australia) indicates a likely effect of hightemperature equilibration on reported values of MPR and MPI-3, but this finding is contingent on the location within the deposit. If metastable equilibrium holds, a third aromatic maturity ratio, $1.5 \times(2-$ $\mathrm{MP}+3-\mathrm{MP}) /(\mathrm{P}+1-\mathrm{MP}+9-\mathrm{MP})(\mathrm{MPI}-1)$, can be used as a proxy for oxidation potential. Values of $\log a_{\mathrm{H}_{2(a q)}}$ determined from data reported for HYC and for a sequence of deeply buried source rocks are indicative of more reducing conditions at a given temperature than those inferred from data reported for two sets of samples exposed to contact or regional metamorphism. These results are limiting-case scenarios for the modeled systems that do not account for effects of non-ideal mixing or kinetics, or external sources or transport of the organic matter. Nevertheless, quantifying the temperature dependence of equilibrium constants of organic reactions enables the utilization of organic maturity parameters as relative geothermometers at temperatures higher than the nominal limits of the oil window.
\end{abstract}

\footnotetext{
${ }^{*}$ Corresponding author

Email address: Jeffrey.Dick@curtin.edu .au (Jeffrey M. Dick)
} 


\section{Introduction}

Hydrocarbons, in particular aromatic compounds, can persist in hydrothermal conditions and in the early stages of rock metamorphism. Price (1993) reported the presence of naphthalene and biphenyl at $450{ }^{\circ} \mathrm{C}$ in aqueous-pyrolysis experiments and predicted that aromatic hydrocarbons might be found at low concentrations at higher temperatures, possibly preserved as inclusions in minerals that have undergone the early stages of rock metamorphism, potentially making organic compounds useful as geothermobarometers. Indeed, the relative abundances of specific aromatic compounds, known as maturity parameters, can be used to infer effects of past igneous and hydrothermal activity on organic-rich systems (George, 1992) and the history of possible ore-forming fluids (Püttmann et al., 1989; Chen et al., 2003; Mackenzie et al., 2008; Williford et al., 2011), but observed reversals or unexpectedly low values of these ratios at high maturity and/or temperature (George, 1992; Raymond and Murchison, 1992; Bechtel et al., 1995; Brocks et al., 2003a, and others) are not accounted for by existing theoretical models. The goal of the present study is to better understand the applications of the aromatic maturity ratios of phenanthrene (P) and methylphenanthrene (MP) in hydrothermal systems by estimating the high-temperature standard Gibbs energies of the species involved and comparing predictions made by thermodynamic calculations with published observations.

The thermodynamic modeling of maturity parameters actually invokes a metastable equilibrium, in which transformations are limited to certain classes of compounds, for example between P and MP. In a metastable equilibrium scenario (Shock, 2000), the organic molecules persist and react with each other over the time scale of interest, instead of transforming to the globally more stable methane, carbon dioxide, water and graphite in the system C-H-O (Shock and Helgeson, 1990; Holloway, 1984). It has already been established that metastable equilibrium states are attainable in hydrothermal systems containing organic molecules (Helgeson et al., 1993; Shock, 2000; Seewald, 2001; Helgeson et al., 2009). The thermodynamic parameters reported in this study can be used to predict the metastable equilibrium abundances of isomers of MP as a function of temperature as well as the abundance ratios for metastable equilibrium among $\mathrm{P}$ and isomers of MP by specifying oxidation-reduction potential in addition to temperature. The hypothesis of metastable equilibrium between isomers is tested using aromatic maturity ratios reported in bitumens extracted from the mineralized zones of the Here's Your Chance (HYC) Pb-Zn-Ag deposit at McArthur River, Northern Territory, Australia (Chen et al., 2003; Williford et al., 2011) and in samples from unmineralized but heated areas associated with regional metamorphism (Brocks et al., 2003a), near igneous intrusions (George, 1992), or in deeply buried sediments (George and Ahmed, 2002). 
The metastable equilibrium model that is proposed provides a potential explanation for observed reversals of some aromatic maturity parameters at high temperature; to our knowledge such a model and its applications have not been described before. The equilibrium model is not applicable to all situations. For example, migration and transport from different sources and mixing of fluids on time scales shorter than those required for metastable equilibrium may be more important in particular samples. Even at high temperatures, alteration of the aromatic compounds during thermal cracking of reservoired petroleum may be primarily kinetically driven (Fusetti et al., 2010a,b). Where equilibration is possible, attainment or progression toward metastable equilibrium can occur through multiple mechanisms. It must be emphasized that the predictions of the equilibrium model carry no implications for mechanisms. Besides interconversion between isomers (transmethylation), preferential degradation or demethylation are other possible pathways by which a metastable equilibrium distribution can be obtained.

The organic matter in some ore deposits, including the HYC deposit, likely results from hydrothermal alteration and transport in aqueous fluids, including potential ore-forming fluids (Brocks et al., 2003b; Chen et al., 2003; Williford et al., 2011; Greenwood et al., 2013). Despite the condensed or surface-bound nature of much sedimentary organic matter, quantifying the behavior of aromatic compounds dissolved in high-temperature aqueous fluids is important for understanding the sources and reactions of organic species in hydrothermal fluids (Price, 1993; Konn et al., 2012), the formation of petroleum in some environments by hydrothermal alteration of organic matter (Kawka and Simoneit, 1990; Ventura et al., 2012), possible formation via abiotic processes on other planets (Zolotov and Shock, 1999), and reactions occurring in hydrous pyrolysis experiments (Kawka and Simoneit, 1994; McCollom et al., 2001, 1999) and in industrial processes (Karásek et al., 2007). Therefore, the thermodynamic properties of aqueous solute species of P and MP are considered in this study. "High temperature" is used here to refer to temperatures exceeding the maximum for the oil window, which in this study is nominally taken to be $130-160{ }^{\circ} \mathrm{C}$, as no single value is applicable to all systems (Hunt, 1996; Giże et al., 2000). Existing estimates of the high-temperature thermodynamic properties of pure crystalline and liquid isomers of MP are limited to the isomers denoted as 1-MP, 2-MP and 4-MP (Richard and Helgeson, 1998), but recent quantum chemical results for the aqueous species (Szczerba and Rospondek, 2010) also include 3-MP and 9-MP. Based on a these and other available data, a compilation of thermodynamic parameters is presented here that may be used for estimates to $\sim 500{ }^{\circ} \mathrm{C}$ of the aqueousspecies standard Gibbs energies. 


\section{Background}

The structures of the species of interest in this study are shown in Fig. 1. In studies of organic maturation, these aromatic hydrocarbons are sometimes referred to as geomarkers (Simoneit, 2005), because the methylated products are formed through geosynthetic pathways, even though the precursor compounds may ultimately be derived from biological sources. Fig. 1 includes a simplified depiction of the major geosynthetic pathways. Geosynthetic pathways of methylation and isomerization of phenanthrene depend to varying extents on mineral catalysts and the energetics of the different isomerization reactions (Smith et al., 1995); in most cases the starting material is likely to be an $\alpha$-methylated isomer (1-MP or 9-MP). 9-MP is an initial product of some geosynthetic pathways (Alexander et al., 1995). Application of the free valence number technique of Burkitt et al. (1951) shows that alkylation at position 1 is highly kinetically favored over 2 and 3 (Karr et al., 1967). 2-MP and 3-MP follow either by rearrangement (methyl shift) or are more susceptible to being formed by methylation at higher temperatures (Alexander et al., 1995; Smith et al., 1995).

\subsection{Thermal maturation and aromatic maturity indices}

The original definitions of maturation of kerogen come from the coal literature, where thermal maturation was defined in terms of the rank of coals or kerogen (Philippi, 1974; Dow, 1977). In kerogen, increasing maturity is associated with increasing reflectance of vitrinite $\left(R_{0}\right)$ (Dow, 1977). Vitrinite reflectance and corresponding paleotemperatures vary between systems, but $R_{0}=1.3 \%$ (Sweeney and Burnham, 1990) and $\sim 130-160{ }^{\circ} \mathrm{C}$ (Hunt, 1996; Giże et al., 2000) can be taken as nominal upper limits to the liquid oil window. At higher temperatures a system may become overmature, signifying the onset of degradation reactions and the end of the liquid oil window (Radke et al., 1982a). However, changes in vitrinite reflectance continue well into the dry gas zone, at temperatures of at least $250{ }^{\circ} \mathrm{C}$, where $R_{0}$ may range from 4-5\% (Hunt, 1996). Various biomarker and geomarker proxies for maturity have been identified, often with attempts to reference them to the original scale of vitrinite reflectance. Biomarker ratios described by van Graas (1990) were calibrated up to a vitrinite reflectance equivalent $\left(R_{0}^{\mathrm{E}}\right)$ of $1.0 \%$, corresponding to the oil/condensate threshold. At higher-maturity conditions, beyond the liquid oil window, aromatic maturity ratios remain useful (Willsch and Radke, 1995; Boreham et al., 1988).

The definitions of aromatic maturity parameters often take account of the degree of conversion from $\alpha$-methyl (e.g. 9-MP, 1-MP, 4-MP) to $\beta$-methyl isomers (2-MP, 3-MP). Three maturity parameters that are considered in our study are the MPR, MPI-3 and MPI-1. See Radke (1987) and George and Ahmed (2002) for more complete lists, including ratios for aromatic compounds other than phenanthrene. The MPR (methylphenanthrene ratio) is defined as (Radke et al., 1982b) 


$$
\mathrm{MPR}=\frac{2-\mathrm{MP}}{1-\mathrm{MP}},
$$

where 2-MP and 1-MP stand for the abundances of the respective MP isomer, methylated at the 1- or the 2- position. Another index that refers only to the relative abundances of the isomers of MP is the MPI-3 (Radke, 1987; Garrigues et al., 1988), defined as

$$
\mathrm{MPI}-3=\frac{2-\mathrm{MP}+3-\mathrm{MP}}{1-\mathrm{MP}+9-\mathrm{MP}+(4-\mathrm{MP})}
$$

Perhaps the most widely used aromatic maturity ratio, the "first methylphenanthrene index" (MPI-1), is defined in terms of abundances of P and isomers of MP (Radke et al., 1982a), and can be written as

$$
\mathrm{MPI}-1=\frac{1.5(2-\mathrm{MP}+3-\mathrm{MP})}{\mathrm{P}+1-\mathrm{MP}+9-\mathrm{MP}}
$$

Another ratio encountered is the "methylphenanthrene distribution fraction" (MPDF) (Kvalheim et al., 1987), which is defined as

$$
\mathrm{MPDF}=\frac{2-\mathrm{MP}+3-\mathrm{MP}}{1-\mathrm{MP}+2-\mathrm{MP}+3-\mathrm{MP}+9-\mathrm{MP}}
$$

Values of MPDF can be converted to MPI-3 according to

$$
\text { MPI-3 = MPDF / (1 - MPDF })
$$

which follows from Eqs. (2) and (4).

Compared to the other ratios given above, the usefulness of MPR as a conventional maturity parameter is supported by a low energy barrier for isomerization found in the ab initio simulations of Szczerba and Rospondek (2010) and experiments showing more rapid interconversion between 1-MP and 2-MP than between the other isomers (Nomoto et al., 2000). In analytical determination of MPR and the other maturity ratios using gas chromatography-mass spectrometry (GC-MS), the relative abundances of the compounds can be used reliably (Mackenzie, 1984). 4-MP and 9-MP may not be separated on some GC columns, but the abundance of 4-MP in natural samples is often small enough that it makes an insignificant contribution to the calculation of MPI-3 and MPI-1 (Radke et al., 1982a). However, 4-MP is not totally absent in nature (e.g. Garrigues and Ewald, 1983).

\subsection{Thermal maturation of organic matter: transitions from kinetic to thermodynamic control}

Maturation is a consequence of chemical reactions that lead to a suite of more stable molecules starting from reactants that generally are not in a state of chemical equilibrium (Tissot and Welte, 1984; 
Willsch and Radke, 1995; Bastow et al., 2000). The basic criterion for usefulness of a maturity parameter is that it continues to change as a result of increased heating or passage of time in the system of interest. Therefore, if a reaction has reached equilibrium it is often assumed that it can no longer be used to indicate further changes in maturity (Mackenzie, 1984). This assumption, however, is not valid if the equilibrium constants, and therefore, the relative abundances of isomers, change significantly with continued increase in temperature. Not only does increased temperature result in increased rates of the maturation reactions (Tissot and Welte, 1984), but heating may also change the directions of the reactions as a result of changes in equilibrium constants (Richard and Helgeson, 1998; Helgeson et al., 1998, 2009). Nevertheless, in interpretations of organic maturity parameters, it is commonly assumed that metastable equilibrium abundance ratios do not change with temperature. For example, in a general discussion of biomarker maturity parameters where compound A reacts to form compound B, Peters et al. (2005) stated that “... after reaching equilibrium, no further information on maturity is available because the ratio $\mathrm{B} /(\mathrm{A}+\mathrm{B})$ remains constant with further heating."

Studies whose results fit the conventional expectation of increasing maturity parameters with increasing time and temperature include that of Love et al. (1996), who found that the coal samples with the highest $R_{o}(1.32 \%)$ had the highest MPR (3.34 in dichloromethane extract; 2.71 in pyrolysate). Davies (1997) documented increasing values of MPR up to $R_{\mathrm{o}}=1.1 \%$. It is not uncommon, however, to find reports of reversals in the aromatic maturity parameters at higher overall maturities. Bechtel et al. (1995) studied organic matter in the Kupferschiefer deposit and found a decrease of MPR in the ore zone. They speculated it might be due to higher reactivity of 2-MP than 1-MP under oxidizing conditions but gave no additional evidence to support this possibility. Simoneit et al. (1992) studied the shallow sediments in the Guaymas Basin and found values of MPI-3 ranging from 0.8 to 1.5 , followed by a mild decrease with depth. George (1992) studied a siltstone and oil shale affected by igneous intrusions in the Midland Valley of Scotland and found values of MPR that increase, then decrease at closest approach to a dyke and a sill. In another study of samples from the Midland Valley, Raymond and Murchison (1992) found ratios of alkylated naphthalenes and phenanthrenes in rapidly heated zones that at first increased, then decreased at higher maturities. A reversal of MPI-1 was apparent by $R_{\mathrm{O}} \approx 2.0 \%$, but MPR did not decrease up to the highest reported $R_{\mathrm{O}}=3.5 \%$. A decrease in MPR, however, was observed by George (1992) at higher maturities $\left(R_{\mathrm{O}} \approx 4.9\right.$ to $\left.5.3 \%\right)$. In a Cretaceous mudstone exposed to peak temperatures of $\sim 300{ }^{\circ} \mathrm{C}$, Sampei et al. (2004) found a strong reversal in the values of MPI-3, that steadily decreased from ca. 3 to 1 in the depth interval of $\sim 4500$ to $5500 \mathrm{~m}$. In a carbonate sequence in the Northern Alps, Radke (1987) observed a decrease in MPR below 2.3 km that was attributed to a "pyrolytic-like" 
source. This term refers to the potential for release of MP from buried kerogens, and the expectation that these MPs released by pyrolytic processes would be more immature, i.e. have ratios of 2-MP/1-MP that are lower than those found in the free MPs. However, consideration of the reported high-temperature reversals in many systems suggests that low values of MPR and MPI-3 observed at high temperatures characteristic of pyrolytic conditions are the result of systematic changes in relative stabilities of isomers that can be modeled by computing the thermodynamic properties of the different isomers.

The idealized progress of MPR or MPI-3 under different realms of kinetic and thermodynamic control is shown in Fig. 2. The initial value of the maturity parameter is determined by source effects, notably the preferred methylation at positions 1 or 9 . The subsequent rise in the parameter results from a kinetic response as the system approaches metastable equilibrium. The realm of kinetic control is limited to relatively low temperatures and time scales shorter than those required for attainment of metastable equilibrium. However, after enough time has elapsed (a shorter duration the higher the temperature), the system reaches a metastable equilibrium, indicated by the vertical dashed line in Fig. 2. After this point, if the temperature continues to increase, the maturity parameter tends to follow the equilibrium trajectory, and the equilibrium constants of the reactions may be such that the metastable equilibrium value of the maturity parameter decreases. The equilibrium distribution represents a limiting case for completion of the conventional kinetically controlled maturation process. Because the equilibrium distribution is a function of temperature, a case can also be made for an "overmature", but dynamic, response that could involve reversals of maturity parameters that would be unexpected in conventional models based only on kinetics.

Organic maturity parameters other than ratios of $\mathrm{P}$ and MP, especially biomarker ratios, have been noted to exhibit reversals (Peters et al., 2005, p. 976). Reversals in methylation patterns for hopanes and triterpanes at high temperature have been reported (Schwab et al., 2005; Raymond and Murchison, 1992), as have reversals or values that are lower than expected for high maturities for maturity parameters based on the stereochemistry of hopanes and steranes (Strachan et al., 1989; Davies, 1997; Arouri et al., 2000), including some examples near igneous intrusions (Bishop and Abbott, 1993, 1995; Othman et al., 2001). The behavior of these and other biomarker ratios is not considered further in this study, but our results suggest that a thermodynamic analysis of the relative stabilities of the biomarkers at high temperature could offer an explanation for some of the reversals that are usually considered to be anomalous. 


\subsection{Need for revised thermodynamic models to describe the high-temperature observations}

A challenging aspect of thermodynamic applications in organic geochemistry is the lack of either experimental data or rigorous theoretical estimates for the high-temperature thermodynamic properties of many compounds of interest. Calculations of metastable equilibrium distributions are based on the differences in Gibbs energies of the species of interest. For a given reaction, the base 10 logarithm of the equilibrium constant $(\log K)$ is related to the standard Gibbs energy change $\left(\Delta G_{r}^{\circ}\right)$ by

$$
\log K=-\Delta G_{r}^{\circ} / 2.303 R T
$$

where $R$ stands for the gas constant and $T$ is the temperature in Kelvin. The standard Gibbs energies can be calculated by combining the enthalpies and entropies of the compounds; an application of this approach for biomarkers was described by van Duin et al. (1997) using enthalpies and entropies estimated using molecular mechanics at 25 and $200{ }^{\circ} \mathrm{C}$. Kolaczkowska et al. (1990) estimated thermodynamic properties of hopane isomers using molecular mechanics. The values of the metastable equilibrium ratios they calculated at high temperatures are subject to greater uncertainty, since only the value for $T$ was changed in Eq. (6) while assuming that the value of $\Delta G^{\circ}$ was invariant with respect to temperature. At $25^{\circ} \mathrm{C}$, work on alkylphenanthrenes includes molecular mechanistic simulations reported by Budzinski et al. (1993) for alkylphenanthrene gases, but they are only restricted to enthalpies. An example of the application of high-temperature thermodynamic data to alkyl-aromatic distributions is the equilibrium calculations of Charlesworth (1987) at $400-600{ }^{\circ} \mathrm{C}$ to model the products of pyrolysis of oil shale, including 1- and 2-methylnaphthalene, dimethylnaphthalenes, P, but no MPs. Given the existing thermodynamic models, there is a poor understanding of the energetic constraints on aromatic maturity parameters at high temperature. In this study we attempt to overcome some of these gaps in understanding, while at the same time being aware of the very limited sources of thermodynamic data.

\section{Estimation of standard molal thermodynamic properties}

We combined data from various sources, in order to estimate the standard molal thermodynamic properties needed for stability calculations at higher temperatures of aqueous phenanthrene and isomers of MP. Our strategy was to combine thermodynamic data for crystalline species estimated using group contribution methods (Richard and Helgeson, 1998), with solution properties (May et al., 1983) to obtain the standard molal thermodynamic properties of aqueous $\mathrm{P}$ and 1-MP. Then we calculated the standard Gibbs energies and enthalpies of the other isomers relative to 1-MP using recently reported values from ab initio quantum chemical simulations (Szczerba and Rospondek, 2010). Values at $25{ }^{\circ} \mathrm{C}$ and 1 bar 
of the standard molal Gibbs energy and enthalpy of formation from the elements $\left(\Delta G_{f}^{\circ}\right.$ and $\left.\Delta H_{f}^{\circ}\right)$ and standard molal entropy, isobaric heat capacity and volume $\left(S^{\circ}, C_{P}^{\circ}\right.$ and $\left.V^{\circ}\right)$ generated in the present study are listed in Table 1. Details of the calculations are given in the footnotes of that Table, and additional notes on the data are provided below.

\subsection{Standard Gibbs energies as a function of temperature}

The standard state adopted for aqueous species other than $\mathrm{H}_{2} \mathrm{O}$ is defined as unit activity of the species in a hypothetical one molal solution referenced to infinite dilution at any temperature and pressure. The standard state adopted for organic liquids and crystalline compounds and liquid $\mathrm{H}_{2} \mathrm{O}$ is one of unit activity of the pure component at any temperature and pressure. The former standard state is sometimes referred to as a Henryan or molal standard state and the latter as a Raoultian or mole-fraction standard state (Anderson and Crerar, 1993).

The apparent standard molal Gibbs energy of a species $\left(\Delta G^{\circ}\right)$ at temperature $T$ and pressure $P$ is given by

$$
\Delta G^{\circ} \equiv \Delta G_{f}^{\circ}+\left(G_{P, T}^{\circ}-G_{P_{r}, T_{r}}^{\circ}\right)
$$

where $\Delta G_{f}^{\circ}$ represents the standard molal Gibbs energy of formation of the species from the elements in their stable forms at $25^{\circ} \mathrm{C}\left(T_{r}\right)$ and 1 bar $\left(P_{r}\right)$, and $G_{P, T}^{\circ}-G_{P_{r}, T_{r}}^{\circ}$ is the difference between the standard molal Gibbs energy of the species at the pressure and temperature of interest and that at $P_{r}$ and $T_{r}$ (Helgeson et al., 1998). In this communication, terminology referring to any standard molal property of an aqueous species is shorthand for the standard partial molal property of that species.

The value of $G_{P, T}^{\circ}-G_{P_{r}, T_{r}}^{\circ}$ can be expressed as

$$
G_{P, T}^{\circ}-G_{P_{r}, T_{r}}^{\circ}=-S_{P_{r}, T_{r}}^{\circ}\left(T-T_{r}\right)+\int_{T_{r}}^{T} C_{P_{r}}^{\circ} d T-T \int_{T_{r}}^{T} C_{P_{r}}^{\circ} d \ln T+\int_{P_{r}}^{P} V^{\circ} d P,
$$

where $C_{P_{r}}^{\circ}$ and $V^{\circ}$ denote the standard molal isobaric heat capacity at $P_{r}$ and standard molal volume of the species. In the case that $C_{P_{r}}^{\circ}$ and $V^{\circ}$ can be considered to be constant, the integrals in Eq. (8) can be evaluated to write

$$
G_{P, T}^{\circ}-G_{P_{r}, T_{r}}^{\circ}=-S_{P_{r}, T_{r}}^{\circ}\left(T-T_{r}\right)+C_{P_{r}}^{\circ}\left(T-T_{r}-T \ln \left(\frac{T}{T_{r}}\right)\right)+V^{\circ}\left(P-P_{r}\right) .
$$

We adopt this equation to calculate the value of $\Delta G^{\circ}$ of the aqueous species at elevated temperatures and pressures. This equation does not account for the temperature or pressure dependence of standard molal heat capacities or volumes of the aqueous species and, in particular, does not represent correctly the behavior of these properties at the critical point of $\mathrm{H}_{2} \mathrm{O}$. Both $C_{P_{r}}^{\circ}$ and $V^{\circ}$ are required to approach infinite values at the critical point, and this property of aqueous solutes at infinite dilution is reproduced 
by models based on Born solvation theory for ions, such as as the revised Helgeson-Kirkham-Flowers (HKF) equations (Helgeson et al., 1981; Tanger and Helgeson, 1988; Shock et al., 1992). The contribution of the simplifications adopted in the present study to uncertainty in calculated standard Gibbs energies at critical and supercritical temperatures and pressures is discussed below.

\subsection{Solubilities of crystalline compounds}

Because the melting points of $\mathrm{P}$ and the isomers of MP are well above $25^{\circ} \mathrm{C}$, the properties of the crystalline compounds are a natural starting point for assessing properties of the aqueous species via solubilities and heats of solution. The standard molal thermodynamic properties of the crystalline compounds used in the present study are based on additive structural group contributions derived from many classes of organic compounds (Richard and Helgeson, 1998). Alternative pathways to thermodynamic properties of aqueous species starting with the properties of liquid compounds could be envisaged; however, the $\Delta G_{f}^{\circ}$ of the liquid 1-MP and 2-MP at $25{ }^{\circ} \mathrm{C}$ tabulated by Richard and Helgeson (1998) are inverted (1-MP more stable) with respect to the crystalline compounds, possibly owing to different reference model compounds used to derive the group contributions for the organic liquids, or because the properties at $25^{\circ} \mathrm{C}$ are those of the supercooled liquids.

Experimental solubilities for crystalline $\mathrm{P}$ at $\sim 25-73{ }^{\circ} \mathrm{C}$ and for $\mathrm{P}$ and 1-MP at $\sim 5-30{ }^{\circ} \mathrm{C}$ were reported by Wauchope and Getzen (1972) and May et al. (1983), respectively. In their study, May et al. (1983) reported the corresponding standard thermodynamic properties using a mole-fraction standard state (Clarke and Glew, 1966). In order to ensure consistency with the molal standard state for aqueous species, we calculated values of the standard molal properties of solution $\left(\Delta G_{s o l}^{\circ}, \Delta H_{s o l}^{\circ}\right.$ and $\Delta C_{P, s o l}^{\circ}$ at 25 ${ }^{\circ} \mathrm{C}$ ) for P and 1-MP using a least-squares fit of Eq. (9). The fit took account of data from both Wauchope and Getzen (1972) and May et al. (1983), and $P$ was set equal to $0.1 \mathrm{MPa}(1 \mathrm{bar}$ ) so no volumetric information was included in the fit. In this procedure, solubilities reported in mole fraction units were converted to Gibbs energies of solution using

$$
\Delta G_{\text {sol }}^{\circ}=-2.303 R T \log m_{P},
$$

where $m_{P}$ stands for the molality of $\mathrm{P}$ in the saturated solution, which in dilute solutions approaching the limit of $x_{\mathrm{H}_{2} \mathrm{O}}=1$ can be calculated from the reported mole-fraction solubilities $\left(x_{P}\right)$ using

$$
m_{P}=N_{W} x_{P}
$$

where $N_{W}=1000 / 18.01528=55.50844$, which is the number of moles of $\mathrm{H}_{2} \mathrm{O}$ in $1 \mathrm{~kg}$ of the pure solvent. 
The values of the parameters at $25{ }^{\circ} \mathrm{C}$ for $\mathrm{P}$ and 1-MP obtained using the least-squares fit are $\Delta G_{\text {sol }}^{\circ}=29807$ and $33405 \mathrm{~J} \mathrm{~mol}^{-1}, \Delta S_{\text {sol }}^{\circ}=37.09$ and $26.58 \mathrm{~J} \mathrm{~K}^{-1} \mathrm{~mol}^{-1}$, and $\Delta C_{P, \text { sol }}^{\circ}=242.42$ and $308.31 \mathrm{~J} \mathrm{~K}^{-1} \mathrm{~mol}^{-1}$, respectively. The corresponding values of $\Delta G_{\text {sol }}^{\circ}$ (molal standard state) at all temperatures calculated using Eq. (9) are lower than those of $\Delta G_{\text {sol }}^{\bullet}$ (mole-fraction standard state used by May et al., 1983) in accord with (cf. Anderson and Crerar, 1993, p. 281)

$$
\Delta G_{\text {sol }}^{\circ}=\Delta G_{\text {sol }}^{\bullet}-2.303 R T \log N_{W}
$$

Note that in the calculation of $\Delta G_{\text {sol }}^{\circ}$ from solubilities, activity coefficients of all aqueous species are taken to be unity.

\subsection{Aqueous species properties from solubility and dissolution properties}

Values of $\Delta G_{\text {sol }}^{\circ}, \Delta H_{\text {sol }}^{\circ}$ and $\Delta C_{P, \text { sol }}^{\circ}$ of $\mathrm{P}$ and 1-MP obtained by regressing the data of May et al., 1983 were combined with the corresponding properties of the crystalline compounds from Richard and Helgeson (1998) to calculate those of the aqueous P and 1-MP listed in Table 1. A value of $12.4 \mathrm{~cm}^{3}$ $\mathrm{mol}^{-1}$ for the volume change of dissolution $\left(\Delta V_{\text {sol }}^{\circ}\right)$ of $\mathrm{P}$ reported by Sawamura (2000) was combined with $V^{\circ}$ for the crystalline compound (Richard and Helgeson, 1998) to generate the value listed for the aqueous species in Table 1. Since no value of $\Delta V_{\text {sol }}^{\circ}$ for MP could be located in the literature, it was estimated using

$$
\Delta V_{\text {sol, } \mathrm{MP}}^{\circ}=\Delta V_{\text {sol }, \mathrm{P}}^{\circ}+\left(V_{\text {toluene }, a q}^{\circ}-V_{\text {benzene }, a q}^{\circ}\right)-\left(V_{\text {toluene }, \text { liq }}^{\circ}-V_{\text {benzene }, l i q}^{\circ}\right),
$$

in which the difference between the volumes of toluene and benzene represents the contribution of the methyl group on an aromatic ring, and the difference between the aqueous and liquid states of toluene and benzene represents the property of dissolution; the liquid state is required because that is the stable state of these compounds at $25^{\circ} \mathrm{C}$, unlike $\mathrm{P}$ and $\mathrm{MP}$ which exist as solids. Using values of $\Delta V_{\text {sol, } \mathrm{P}}^{\circ}=12.4$ $\mathrm{cm}^{3} \mathrm{~mol}^{-1}$ taken from Sawamura (2000), and values of $V^{\circ}$ of toluene and benzene in the aqueous and liquid states taken from Shock and Helgeson (1990) and Helgeson et al. (1998), respectively, we calculated $\Delta V_{\text {sol, } \mathrm{MP}}^{\circ}=9.7 \mathrm{~cm}^{3} \mathrm{~mol}^{-1}$.

Owing to the lack of available data, we adopted the single estimated value for $\Delta V_{\text {sol, MP }}^{\circ}$ and that for $\Delta C_{P, s o l, 1-\mathrm{MP}}^{\circ}$ to be representative of all of the isomers of MP. These values were combined with the values of $V^{\circ}$ and $C_{P}^{\circ}$ for crystalline 1-MP, 2-MP and 4-MP (Richard and Helgeson, 1998) to calculate the corresponding values for the aqueous species listed in Table 1. Because the properties of crystalline 3-MP and 9-MP were not reported by Richard and Helgeson (1998), $V^{\circ}$ and $C_{P}^{\circ}$ of the aqueous species of 3-MP and 9-MP were estimated to be equal to those of 2-MP and 1-MP, respectively. However, the 
availability of simulation data for the relative enthalpies and Gibbs energies of the isomers of MP permits calculations of these standard molal properties that are unique for each isomer, as described below.

\subsection{Aqueous species enthalpies and Gibbs energies from reported ab initio simulations}

For $\mathrm{P}$ and 1-MP, values of $\Delta H_{s o l}^{\circ}$ and $\Delta G_{s o l}^{\circ}$ at $T_{r}$ described above were combined with those of $\Delta H_{f}^{\circ}$ and $\Delta G_{f}^{\circ}$ of the crystalline species to generate the corresponding values for the aqueous species shown in Table 1. The standard molal entropies $\left(S_{P_{r}, T_{r}}^{\circ}\right)$ at the reference pressure $\left(P_{r}\right)$ and temperature $\left(T_{r}\right)$ shown in this table were calculated using

$$
\Delta G_{f}^{\circ}=\Delta H_{f}^{\circ}-T_{r} \Delta S_{f}^{\circ}
$$

and

$$
\Delta S_{f}^{\circ}=S_{P_{r}, T_{r}}^{\circ}-S_{\text {elements }}^{\circ}
$$

where $P_{r}$ is 1 bar, $T_{r}$ is $298.15 \mathrm{~K}$ and $S_{\text {elements }}^{\circ}$ represents the sum in one mole of the compound of the entropies of the elements in their stable form at $T_{r}$ (Cox et al., 1989).

For other MP isomers, we combined the standard molal Gibbs energy and enthalpy of formation of $\mathrm{P}$ and 1-MP with reported relative Gibbs energies and enthalpies from quantum chemical simulations (Szczerba and Rospondek, 2010) to generate the standard molal properties for 2-MP, 3-MP, 4-MP and 9-MP. In the study of Szczerba and Rospondek (2010) the energies of the isomers of MP were expressed relative to the most stable isomer (2-MP), which was assigned an arbitrary value of zero for Gibbs energy and enthalpy. The model for water used by Szczerba and Rospondek (2010) was an implicit solvent model (polarizable continuum model; PCM) at ambient conditions ( $298 \mathrm{~K})$.

We are aware of one other estimated value for the standard Gibbs energy of aqueous P, estimated by Dolfing et al. (2009) as $307.24 \mathrm{~kJ} / \mathrm{mol}$, which is ca. $2 \%$ greater than the value listed in Table 1 . The difference can be attributed primarily to the method of Dolfing et al. (2009) to calculate $\Delta G_{f}^{\circ}$ of the aqueous species which involved combining a solubility measurement with the $\Delta G_{f}^{\circ}$ of the liquid $\mathrm{P}$, instead of the crystalline compound; the latter approach is favored here as the crystalline $\mathrm{P}$ is the stable state at $25^{\circ} \mathrm{C}$.

A single, temperature-invariant heat capacity (Table 1) for the aqueous species is an approximation necessitated by the scarcity of high-temperature calorimetric data, which are difficult to obtain in part because of the low solubilities of the compounds of interest. Note, however, that the thermodynamic data for crystalline compounds referred to below were taken from Richard and Helgeson (1998), who do provide a heat capacity function for the crystalline compounds in the form of the Maier-Kelley equation (Maier and Kelley, 1932). Because of the limitations of the model adopted in the present study, calcu- 
lations of the standard molal Gibbs energies of the aqueous species at high temperature and pressure using Eq. (9) are subject to increased uncertainties, as described below. In terms of the relative stabilities of the isomers, however, the current data set provides a provisional approximation of the effects of increasing temperature beyond the oil window.

\section{Calculation of solubilities, maturity ratios, and uncertainties}

\subsection{Solubility as a function of temperature}

A comparison between the solubilities at $25{ }^{\circ} \mathrm{C}$ of phenanthrene $(\mathrm{P})$ and isomers of methylphenanthrene (MP) calculated in this study and values from experiments and another estimation algorithm is presented in Table 2. The calculated solubilities are based on the differences in the standard Gibbs energies of P and isomers of MP between crystalline (Richard and Helgeson, 1998) and aqueous (Table 1) states, but the values of $\Delta G_{f}^{\circ}$ of crystalline 3-MP and 9-MP were approximated as being equal to those of 2-MP and 1-MP, respectively. The calculated solubility of $\mathrm{P}$ is between the values reported by Wauchope and Getzen (1972) and May et al. (1983), and that for 1-MP is in close agreement with the value reported by May et al. (1983). This result is not surprising since these experimental data were used in our fits of Eq. (9). Experimental solubilities of the other isomers of MP are poorly documented. One value for 2-MP appears in the tabulation of Isnard and Lambert (1989) but no source is given. The experimental solubility of 9-MP listed in Table 2 is actually derived from the solubility of $\mathrm{P}$ adopted in this study and the observation made by Rogoff (1962) that "The ultraviolet spectra of the compounds show that phenanthrene is only 2.4 times more soluble in water than 9-methylphenanthrene." Our estimated solubility for 9-MP is greater by only $\sim 0.03 \mathrm{mg} / \mathrm{L}$ than the value implied by the statement of Rogoff (1962), but our calculated solubility for 2-MP diverges to a greater extent from that tabulated by Isnard and Lambert (1989). A different estimation algorithm available in the EPISuite (U.S. Environmental Protection Agency, 2011) is based on a correlation between solubility and the octanol-water partition coefficient (Meylan et al., 1996). The values calculated using the EPISuite (algorithm: WSKOW v1.41) via ChemSpider (http://www.chemspider.com) are lower than experimental values and values calculated in this study, except for 4-MP. Our estimated solubility for 4-MP is much lower than the other isomers, owing to a large offset in $\Delta G^{\circ}$ relative to the other isomers reported by Szczerba and Rospondek (2010) that is not equally manifested in the difference between the pure isomers in the crystalline solid state (Richard and Helgeson, 1998). The position of the methyl group in 4-MP produces a strained conformation, contributing to the relatively higher Gibbs energies of this isomer compared to the others in the gaseous, condensed and aqueous phases (Richard and Helgeson, 1998; Szczerba and Rospondek, 2010). It is not evident that the unfavorable steric interactions should also lead to a decrease in solubility 
(transfer between condensed and aqueous phases), so further work is needed to verify the low predicted solubility.

The solubilities calculated for $\mathrm{P}, 1-\mathrm{MP}, 2-\mathrm{MP}$ and 4-MP as a function of temperature are shown in Fig. 3. The calculated values compare favorably with the experimental values for both $\mathrm{P}$ and 1-MP (May et al., 1983). The experimental solubilities of P reported by Wauchope and Getzen (1972) extend to higher temperatures, and at similar temperatures are somewhat greater than, those of May et al. (1983); the values reported by Wauchope and Getzen (1972) are accordingly also greater than our calculated values. Note in Fig. 3 that 1-MP and 2-MP are predicted to be more soluble than $\mathrm{P}$ above $\sim 150$ and 210 ${ }^{\circ} \mathrm{C}$, respectively. Experimental measurements of the temperature dependence of solubilities of the other isomers of MP are not available so it is not possible to make comparisons to experiments of all of the solubility predictions at this time.

\subsection{Metastable equilibrium ratios of isomers: $M P R$ and MPI-3}

The standard Gibbs energies of the aqueous species computed using Eqs. (7) and (9) can be used to calculate the values of MPR, MPI-3 and MPI-1 (Eqs. 1-3) at metastable equilibrium. The value of MPR can be obtained by first writing the reaction

$$
1-\mathrm{MP} \rightleftharpoons 2-\mathrm{MP},
$$

for which the logarithmic analog of the law of mass action is

$$
\log K=\frac{-\Delta G_{r}^{\circ}}{2.303 R T}=\log \frac{a_{2-\mathrm{MP}}}{a_{1-\mathrm{MP}}},
$$

where $\Delta G_{r}^{\circ}$ denotes the change in the standard Gibbs energy of Reaction 16. If the activity coefficients of 1-MP and 2-MP are taken to be unity, or are equal to each other, then the activity ratio in Eq. (17) corresponds to the definition of MPR given in Eq. (1). Because the MPI-3 ratio (Eq. 2) involves more than two compounds, it is not possible to explicitly calculate the metastable equilibrium ratio using an expression based on the equilibrium constant of a single reaction. Instead, we used the CHNOSZ package (Dick, 2008) for the R software environment (R Core Team, 2012) to calculate the metastable equilibrium ratios of isomers using the thermodynamic data listed in Table 1.

The values of $\Delta G_{r}^{\circ}$ for the reaction of 2-MP to each of the other isomers of MP are shown in Fig. 4a. Values of MPR calculated using Eqs. (7), (9) and (17) together with parameters from Table 1 are shown in Fig. 4b as a function of temperature. For comparison, metastable equilibrium values of MPR calculated using standard Gibbs energies of the crystalline compounds with parameters from Richard and Helgeson (1998) are shown by the dashed line appearing in Fig. 4b. The equilibrium values calculated 
for MPI-3 as a function of temperature are shown in Fig. 4c. An accompanying line for the crystalline species is not shown because the requisite properties of crystalline 3-MP and 9-MP were not reported by Richard and Helgeson (1998). The main result appearing in Fig. 4a is that the difference between the standard Gibbs energies of 2-MP and 1-MP decreases with increasing temperature, becoming equal at $\sim 415{ }^{\circ} \mathrm{C}$. Therefore, the metastable equilibrium value of MPR shown in Fig. $4 \mathrm{~b}$ decreases with increasing temperature, going through unity at $\sim 415{ }^{\circ} \mathrm{C}$. The metastable equilibrium value of MPI-3 shown in Fig. 4c also decreases with increasing temperature, in accord with the decrease in the standard Gibbs energies of both 1-MP and 9-MP relative to 2-MP and 3-MP. The decreases in MPR and MPI3 are consistent with reversals of these parameters at high thermal maturities as discussed earlier, as equilibrium effects become more dominant than kinetic effects in a system undergoing maturation at high temperature (Fig. 2).

\subsection{Propagation of uncertainties in parameters}

There are uncertainties in the calculations as a consequence of uncertainties in the thermodynamic parameters; these theoretical uncertainties can be estimated independently of analytical uncertainties for values of the maturity parameters observed in experiments or field studies. This estimation of uncertainty is essential, given the paucity of experimental data. A propagation of uncertainty to $\Delta G^{\circ}$ at high temperature based on uncertainties in the parameters at $25^{\circ} \mathrm{C}$ was performed, followed by an estimate of the additional uncertainty introduced by neglect of the temperature dependence of $C_{P}^{\circ}$ and $V^{\circ}$.

Residuals between experimentally and mathematically derived thermodynamic properties at $25^{\circ} \mathrm{C}$ of the crystalline compounds reported by Richard and Helgeson (1998) ranged from $1 \%$ in $C_{P}^{\circ}$ to $9 \%$ in $\Delta H_{f}^{\circ}$ of 4-MP (Chirico et al., 1989), and $4 \%$ in $\Delta H_{f}^{\circ}$ of P (Coleman and Pilcher, 1966; Finke et al., 1977). Because of the reliance in the present study on a combination of sources (crystalline species, solubilities, and relative properties of aqueous species from reported $a b$ initio calculations), there is no definitive value of uncertainty that can be assigned to the properties listed in Table 1 for the aqueous species. Therefore, maximum estimates of uncertainty in the parameters at $25{ }^{\circ} \mathrm{C}$ were provisionally made and propagated to higher temperatures. A nominal $\pm 10 \%$ uncertainty is adopted for the difference in $\Delta G^{\circ}$ at $25^{\circ} \mathrm{C}$ between 2-MP and each of the other isomers of MP (not to the values of $\Delta G^{\circ}$ of the individual isomers) that are shown in Fig. $4 \mathrm{a}$. A $\pm 10 \%$ uncertainty in differences in the values of $S^{\circ}$ and

$C_{P}^{\circ}$ between isomers is also adopted, and the uncertainties propagated to higher temperatures assuming uncorrelated errors in Eq. (9) using standard uncertainty propagation techniques.

A notable outcome of the uncertainty analysis appearing in Fig. 4a is the broad range of temperature, $\sim 375$ to $455^{\circ} \mathrm{C}$, over which the $\Delta G^{\circ}$ of 1-MP and 2-MP may be considered to be equal. The ability of the 
model to predict the actual temperature where the crossover occurs is further challenged by the approach to infinity of the heat capacity and volume at the critical point $\left(\sim 374{ }^{\circ} \mathrm{C}\right)$; these additional uncertainties are addressed below. The estimates of uncertainty in differences of $\Delta G^{\circ}$ between isomers are used to compute uncertainties in the metastable equilibrium values of MPR and MPI-3 shown in Fig. 4b and c, again using the standard error propagation method for uncorrelated errors. The numerical values of uncertainty in MPR and MPI-3 decrease with increasing temperature, but this is due to the decrease in the values of MPR and MPI-3 themselves; the fractional uncertainty in each of these parameters increases with temperature in a manner consistent with the broadening of the uncertainty bars apparent in Fig. 4a. For example, the uncertainty in temperature apparent in Fig. $4 \mathrm{~b}$ at MPR=2.5 is $\sim 160$ to 220 ${ }^{\circ} \mathrm{C}$, while that at MPR=1, in accord with the zone where $\Delta G^{\circ}$ of 1-MP and 2-MP are equal in Fig. 4a, is $\sim 375$ to $455{ }^{\circ} \mathrm{C}$. Therefore, unless uncertainties in the differences in values of $\Delta G_{f}^{\circ}, S^{\circ}$ and $C_{P}^{\circ}$ for pairs of isomers at $25{ }^{\circ} \mathrm{C}$ and 1 bar can be shown to be much less than $\pm 10 \%$, in applications of the metastable equilibrium model to interpret parameters such as MPR and MPI-3, greater emphasis should be placed on relative temperatures along thermal gradients than on absolute temperatures inferred from the calculation, especially at higher temperatures.

\subsection{Model uncertainties}

Besides uncertainties in the parameters appearing in Eq. (9) and listed for the species of interest in Table 1, additional uncertainties in the calculations of $\Delta G^{\circ}$ at high temperature and pressure are introduced by the assumption of constant standard partial molal heat capacity and volume of aqueous species. In reality, these properties are a function of temperature and pressure, but the dependence is especially profound near the critical point of $\mathrm{H}_{2} \mathrm{O}$, where these properties are required to approach infinite values. There is a lack of sufficient experimental data to constrain these temperature-dependent functions for $C_{P}^{\circ}$ and $V^{\circ}$ to characterize the differences between the isomers of MP, using either equationfitting to the data or correlation methods to estimate parameters. An analysis is performed below to estimate the range of error introduced by the simplified model on calculations of the relative stabilities of the MP isomers. It appears from this analysis that the assumption of constant $C_{P}^{\circ}$ and $V^{\circ}$ permits a provisional estimation of the relative stabilities of the isomers that can be used for the major questions regarding interpretation of field and laboratory data presented later in this study. However, caution should be exercised if the equation of state described by Eq. (9) is combined with equations used in extant thermodynamic databases to simulate the consequences of reactions between $\mathrm{P}$ or MP and compounds with dissimilar structures.

An approach based on solvation contributions to the energy has been used by previous workers to 
calculate standard partial molal thermodynamic properties of aqueous organic solutes near the critical point (e.g. Shock and Helgeson, 1990; Plyasunov and Shock, 2001). In the revised HKF equations of state for aqueous species (Helgeson et al., 1981; Tanger and Helgeson, 1988; Shock et al., 1992), the species-dependent Born coefficient $(\omega)$ provides a description of the properties of ions that are influenced by solvation effects. The solvation contributions generally increase with temperature, in addition to exhibiting asymptotic behavior near the critical point. Effective Born coefficients for neutral organic species have been devised on the basis of experimental and predicted high-temperature behavior (Shock and Helgeson, 1990). To assist in the prediction of high-temperature properties of aqueous organic species for which experimental data are lacking, a correlation between $\omega$ and the standard Gibbs energy of hydration $\left(\Delta G_{\text {hyd }}^{\circ}\right)$ at $25{ }^{\circ} \mathrm{C}$ was developed by Plyasunov and Shock (2001). The hydration process is the transfer of a molecule in the gas phase to the aqueous solution. If sufficient data are available, $\Delta G_{\text {hyd }}^{\circ}$ can be computed by combining the solubility (transfer of a molecule in the condensed phase to the aqueous phase; $\Delta G_{\mathrm{sol}}^{\circ}$ ) with the vapor pressure of the pure substance.

The monoaromatic benzene $\left(\Delta G_{\mathrm{hyd}}^{\circ}=4.29 \mathrm{~kJ} / \mathrm{mol}\right)$ and its methylated counterpart toluene $\left(\Delta G_{\text {hyd }}^{\circ}=\right.$ $4.55 \mathrm{~kJ} / \mathrm{mol}$ ) were included in the correlation with $\omega$ described by Plyasunov and Shock (2001), but sufficient data for PAHs, including independent estimates of $\omega$, were not available. The values of $\Delta G_{\mathrm{hyd}}^{\circ}$ themselves carry substantial uncertainty, but possibly decrease for PAHs with larger rings; Amidon and Anik (1980) estimated a value of $\Delta G_{\mathrm{hyd}}^{\circ}=14.21 \mathrm{~kJ} / \mathrm{mol}$ for benzene and $\Delta G_{\mathrm{hyd}}^{\circ}=1.50$ for phenanthrene. Because of the lack of reported vapor pressure and solubility measurements that could be used to calculate $\Delta G_{\text {hyd }}^{\circ}$ for the individual MP isomers, currently it is not possible to characterize the differences in the effective Born coefficient $(\omega)$ for the different isomers based on the correlations of Plyasunov and Shock (2001). To estimate the possible size of uncertainty introduced by this lack of data, the difference between $\Delta G_{\text {hyd }}^{\circ}$ of benzene and toluene of $0.26 \mathrm{~kJ} / \mathrm{mol}$ was used to assign a maximum value of $2 \mathrm{~kJ} / \mathrm{mol}$ to the difference between the $\Delta G_{\text {hyd }}^{\circ}$ of any two isomers of MP. This value takes into account the greater number of configurations of the methyl groups in the MP isomers relative to toluene, and is also approximately equal to the greatest difference in the $\Delta G_{\text {sol }}^{\circ}$ between MP isomers (1-MP and 4-MP) at $25{ }^{\circ} \mathrm{C}$. Uncertainties were then derived from a comparison of results for calculations made with $\Delta G_{\mathrm{hyd}}^{\circ}=0$ and $2 \mathrm{~kJ} / \mathrm{mol}$ to provide a starting point for addressing the effects of differences between the isomers of MP.

Using values of $\Delta G_{\text {hyd }}^{\circ} \approx 0$ and $2 \mathrm{~kJ} / \mathrm{mol}$, values of the Born coefficient $\omega$ calculated according to Eq. (8) of Plyasunov and Shock (2001) are -96726 and $-104801 \mathrm{~J} / \mathrm{mol}$, respectively. These values of $\omega$ can be inserted into the revised HKF equations to calculate the differences in solvation contributions to standard Gibbs energies of species at high temperature, and, therefore, to address the consequences of 
temperature dependent heat capacity and volume parameters, which have not been explicitly considered in the present study (Eq. 9). The differences in the solvation contributions of the standard Gibbs energies of species having these values of $\omega$ at representative conditions are $-164 \mathrm{~J} / \mathrm{mol}$ at $300{ }^{\circ} \mathrm{C}$ and $86 \mathrm{bar}$, $-1137 \mathrm{~J} / \mathrm{mol}$ at $373.917^{\circ} \mathrm{C}$ and $220.46 \mathrm{bar},-548 \mathrm{~J} / \mathrm{mol}$ at $500{ }^{\circ} \mathrm{C}$ and $1000 \mathrm{bar}$, and $-260 \mathrm{~J} / \mathrm{mol}$ at 500 ${ }^{\circ} \mathrm{C}$ and 2000 bar. The first two $T, P$ pairs correspond to pressures along the vapor-liquid coexistence curve for $\mathrm{H}_{2} \mathrm{O}$; the second of these are the critical-point conditions reported by Levelt-Sengers et al. (1983) that are implicit in calculations of solvation properties using the revised HKF equations (Shock et al., 1992) as implemented in SUPCRT92 (Johnson et al., 1992) and, by extension, in CHNOSZ (Dick, 2008). The third and fourth represent the highest temperatures considered in this study, at two different pressures. Notably, the magnitudes of all but the second Gibbs energy difference are smaller than the errors propagated from uncertainties in the thermodynamic data that are shown in Fig. 4a. As expected, the difference in Gibbs energy associated with the provisional maximal difference in Born coefficients between solutes is largest at the critical point. At temperatures above the critical point, the difference decreases with increasing pressure. Therefore, the major conclusions reached in this study based on the computed relative stabilities of isomers are not unduly affected by the unaccounted-for solvation contributions below ca. $300{ }^{\circ} \mathrm{C}$, or at supercritical temperatures at pressures above ca. 2000 bar. In the critical region, the actual Gibbs energies of the solutes are expected to differ to a greater extent from those calculated in this study, but the differences may be less than the largest value calculated $(-1137$ $\mathrm{J} / \mathrm{mol}$ ) if the differences between the Born coefficients $(\omega)$ are smaller than the maximum value used to make the calculations described here.

\subsection{Comparison with field-derived and experimental values of MPR and MPI-3}

The computed metastable equilibrium values of MPR as a function of temperature for aqueous 2MP and 1-MP are compared with various experimental and field-derived data in Fig. 5. The metastable equilibrium values for aqueous species are shown for reference only and are not meant to imply that all experimental or natural systems shown consist of aqueous solutions of methylphenanthrene. Instead, the aqueous solution is a reference state that is useful primarily because of the availability of hightemperature estimates of thermodynamic data for a greater number isomers of MP as aqueous species (this study) than as crystalline or liquid species (Richard and Helgeson, 1998), permitting comparisons with a greater number of aromatic maturity parameters used in organic geochemistry. The metastable equilibrium values of MPR are shown for two pressures, $0.1 \mathrm{MPa}(1 \mathrm{bar})$ and $200 \mathrm{MPa}$ (2000 bar). It can be seen that the uncertainties present in the calculation (as shown in Fig. 4b) do not justify more than a relative consideration of pressure effects. Because the effect of higher pressure is to decrease the 
metastable equilibrium value of MPR (Fig. 5), an increase in pressure with increasing depth or a change from hydrostatic to lithostatic conditions would magnify the expected drop in MPR as equilibrium is approached at high temperatures, but the expected effects of pressure on MPR become smaller with increasing temperature.

The metastable equilibrium value of MPR at $25{ }^{\circ} \mathrm{C}$ and 1 bar shown in Fig. 5 is based on the relative Gibbs energies of the species from the quantum chemical simulations of Szczerba and Rospondek (2010), and is higher than any reported values from field or laboratory studies. However, with increasing temperature, the metastable equilibrium value of MPR decreases, to the extent that it passes through the range of MPR observed in mature source rocks (Radke, 1987; George and Ahmed, 2002) at temperatures approximating those at the end of the oil window. The convergence of the predicted values with the field observations helps to confirm the thermodynamic properties used in the calculations. With a further increase in temperature, the metastable equilibrium line shown in Fig. 5 passes through the range of MPR measured by Brocks et al. (2003a) for bitumens in Archean rocks exposed to low metamorphic grades (ca. $200-300{ }^{\circ} \mathrm{C}$ ). We have plotted only the data for the Hamersley Group reported by Brocks et al. (2003a), as these samples may be subject to less contamination and migration than those from the Fortescue Group (Brocks, 2011). In applying the conventional kinetic interpretation of the aromatic maturity parameters, Brocks et al. (2003a) noted that the MPR ratios were indicative of a lower maturity, and therefore in conflict with high maturities (wet gas or overmature zone) deduced from other molecular indicators in the bitumen (sterane and hopane ratios, and presence of diamondoids). Our results help to reconcile these conflicting observations, as values of MPR reported by Brocks et al. (2003a) can now be interpreted as reflecting equilibration of the MP ratios at higher temperatures than the oil window.

Among the experiments starting with pure compounds, Nomoto et al. (2000) reacted 1-, 2-, 3- and 9MP at $250-400{ }^{\circ} \mathrm{C}$ in the presence of a clay (Na-montmorillonite) catalyst, and reported the abundances of the isomers at the end of the experiments. They found rapid interconversion between 1-MP and 2MP and decrease of the 2-MP/1-MP ratio with temperature. The metastable equilibrium line shown in Fig. 5 has a similar slope, but is lower than, the experimental trend of Nomoto et al. (2000). The reason for this offset may be related to lack of an aqueous solution, as Nomoto et al. (2000) used pure compounds, which were liquid under the experimental conditions. In any case, the effects of changing temperature on the abundance ratios of the isomers in the experiments of Nomoto et al. (2000) have a similar slope as the metastable equilibrium line. The experiments of Voigtmann et al. (1994) had P as a starting compound; 4- to 3-, and 1- to 2-methyl shifts were observed at temperatures from 230-360 ${ }^{\circ} \mathrm{C}$. The positive change of MPR with temperature in the experiments of Voigtmann et al. (1994) might 
indicate that the lower-temperature experimental results were primarily kinetically limited.

Two other experimental studies of MP isomerization using mineral catalysts are those of Alexander et al. (1995) and McCollom et al. (1999) but neither of these studies reported the relative abundances of the isomers of MP. Alexander et al. (1995) reacted P in the presence of Ca-montmorillonite at 100 ${ }^{\circ} \mathrm{C}$ and McCollom et al. (1999) found small amounts of MP when P was reacted with formic acid in hydrous pyrolysis experiments at $330{ }^{\circ} \mathrm{C}$. Pyrolysis experiments on pure compounds reported by $\mathrm{Wu}$ et al. (2002) and on kerogens and bitumens by Garrigues et al. (1990) and Brocks et al. (2003b) did not include catalysts and were unlikely to have approached metastable equilibrium, which is evidenced by the reported increases of experimental MPR with temperature, in contrast to the decreasing trend apparent in Fig. 4a. In the methylation experiments of Smith et al. (1995), coal was included as both a reactant (hydrogen donor) and catalyst; however, the increase of MPI-3 at temperatures up to $400{ }^{\circ} \mathrm{C}$ again is consistent with a departure from a metastable equilibrium distribution of products.

Values of MPI-3 in artificial maturation of kerogen and coal reported by Garrigues et al. (1990) rise exponentially from ca. 250 to $420{ }^{\circ} \mathrm{C}$ to a maximum of $\sim 6.8$, then drop in an approximately linear fashion to $\sim 2.2-3.2$ at $500{ }^{\circ} \mathrm{C}$ (their Figure 3). The rise in MPI-3 at temperatures below $\sim 400{ }^{\circ} \mathrm{C}$ was interpreted by Garrigues et al. (1990) to be the result of rearrangements to the more stable $\beta$ isomers (2-MP and 3-MP); this interpretation is consistent with the relative stabilities of the isomers indicated by metastable equilibrium values $>1$ of MPI-3 shown in Fig. 4 below $\sim 350{ }^{\circ} \mathrm{C}$. At higher temperatures, the experiments of Garrigues et al. (1990) indicated that demethylation of MP was significant, such that dimethylphenanthrenes were not observable, but the disappearance of MPs was not complete (their Figure 5). Garrigues et al. (1990) concluded that "Use of the indices is not possible after $400^{\circ} \mathrm{C}$, since the thermal decomposition of methylated phenanthrenes becomes more important than the methyl $\alpha, \beta$ shifts." Their conclusion, however, does not give any specific explanation for the sharp drop in MPI-3 they observed at temperatures $>420{ }^{\circ} \mathrm{C}$.

Partial dealkylation of MPs at temperatures above $\sim 400{ }^{\circ} \mathrm{C}$ should not preclude the possibility that the net effect of the dealkylation reactions and other specific mechanisms is to preferentially decrease the abundances of the less stable compounds, with a retention of metastable equilibrium. At temperatures above $\sim 400{ }^{\circ} \mathrm{C}$, the crossing of the curves below unity in Fig. $4 \mathrm{c}$ indicates that the more stable isomers are the $\alpha$ isomers instead of the $\beta$ isomers. The offsets between the data of Garrigues et al. (1990) and the metastable equilibrium values shown in Fig. $4 \mathrm{c}$ does still indicate a considerable degree of kinetic control in their experiments, as expected on a short time scale; the thermodynamic analysis however provides an explanation for the observed drop in experimental MPI-3 at temperatures $>420{ }^{\circ} \mathrm{C}$. 


\section{Applications: testing for equilibrium, and development of a redox proxy}

\subsection{Equilibration of MPR and MPI-3 in non-mineralized samples}

In Fig. 6, values of MPI-3 and MPR reported by George (1992), George and Ahmed (2002), Williford et al. (2011) and Chen et al. (2003) are compared with the equilibrium model. All four literature sources give measurements of MPR and MPI-3 (or MPDF, which was converted to MPI-3 using Eq. 5) along a presumed or likely thermal gradient. The plots in Fig. 6 show calculated values of apparent temperature $\left(T_{\mathrm{app}}\right)$ in a hypothetical situation where the values of MPR or MPI-3 represent metastable equilibration among the isomers; the equilibrium $T_{\text {app }}$ are represented by the lines in Fig. 4 . The plots in Fig. 6 are useful for testing the hypothesis of metastable equilibrium between isomers of MP. There are two conditions for equilibrium: 1 ) at equilibrium, the $T_{\text {app }}$ computed using MPR and MPI-3 should be equal; 2) at equilibrium the values of $T_{\text {app }}$ should increase in proximity to the presumed heat source. In case increasing values of $T_{\text {app }}$ are observed, but they are not equal for both MPR and MPI-3, the maturity ratios may be influenced by reactions progressing toward, but not having attained, metastable equilibrium.

Two examples of the onset of equilibration in isomer ratios are shown in Fig. 6a and b. The values of MPR and MPI-3 (calculated from MPDF) in a Dinantian (Lower Carboniferous) siltstone in the Midland Valley of Scotland decrease sharply at the closest proximity to the Spouthead dyke of Permian age (George, 1992). A conventional kinetically controlled maturity model, which would predict increase in MPR and MPI-3 at the highest maturities, does not explain the decrease in these parameters. However, in the equilibrium model, $T_{\mathrm{app}}$ is seen to increase at the final approach to the dyke (arrow in Fig. 6a), which is consistent with a tendency toward equilibration of the isomers brought on by a local pulse of heat. The increase in $T_{\text {app }}$ in the other direction, away from the dyke, corresponds to low but increasing values of MPR and MPI-3 during the kinetic leg of the maturity sequence (cf. Fig. 2), and these values of $T_{\text {app }}$ (represented by open symbols in Fig. 6) should not be regarded as representing any real temperature or signal of equilibration.

In the deepest parts of the McManus-1 core of the middle Velkerri Member in the McArthur Basin in Australia, George and Ahmed (2002) reported values of MPR that exhibit greater scatter and some reversing trends at depth. A decrease in this parameter at high maturities is not expected in conventional models for kinetically controlled maturation process. The metastable equilibrium model gives an increase in $T_{\text {app }}$ to the right of the arrow in Fig. 6b, occurring at temperatures $\sim 200{ }^{\circ} \mathrm{C}$, which are geologically reasonable for a basin like this. We regard the hypothesis of equilibration to be unlikely for the samples represented by open symbols in Fig. 6b, where kinetically controlled maturation is the most 
likely explanation. An alternative explanation for the reversing trend at depth is that a decrease in MPR or MPI-3 can be caused by transport of less altered organic matter from other locations. However, if the transport is from deeper zones, transport may help to preserve a high-temperature equilibrium signal, since deeper areas would be hotter and more likely to equilibrate toward lower values of MPR and MPI3 , and transport upward would tend to cool the reactants and slow their interconversion or preferential degradation.

\subsection{Equilibration of MPR and MPI-3 in mineralized samples}

The McArthur River, or "Here's Your Chance" (HYC) Pb-Zn-Ag deposit in the Northern Territory, Australia is a well-studied deposit from the perspective of aromatic compounds found in the bitumens associated with both the mineralized and non-mineralized zones (Chen et al., 2003; Mackenzie et al., 2008; Williford et al., 2011; Holman et al., 2012). The HYC ore deposit is a sediment-hosted base metal deposit that most likely formed as a consequence of infiltrating hydrothermal fluids from the Emu fault zone, to the north and north-east of the mine (Large et al., 1998), but the depths at which the fluids were sourced, and the degree to which the deposition of the metal sulfides in the ore deposit is syngenetic or epigenetic, continues to be a matter of debate (Logan et al., 2001).

Both Chen et al. (2003) and Williford et al. (2011) suggested that the aromatic compounds they isolated from the samples formed as a result of heating by possible ore fluids, but whether the compounds recorded were in situ or transported from deeper regions has not been conclusively demonstrated. Chen et al. (2003) studied the \#2 orebody, and proposed temperatures greater than $250{ }^{\circ} \mathrm{C}$ to explain the presence of PAHs including pyrene, benzo(e)pyrene, benzo(ghi)perylene and chrysene. Two of the sampling locations (2E4/G 1 and 2E3/9 3) were in the northern portion of the mine, closer to the source of the mineralizing hydrothermal fluids and therefore regarded by Chen et al. (2003) as representing "hotter" conditions than the two ore samples from the other "cooler" locality (2H9/1C). Williford et al. (2011) studied the stratigraphically higher \#5 orebody along a north-south transect, and concurred with these temperatures for formation of PAHs, and also suggested that the PAHs migrated upward with the ore-forming fluids, cooling to $\sim 200{ }^{\circ} \mathrm{C}$ where mineralization occurred. In the study of Chen et al. (2003), the aromatic maturity ratios were shown to exhibit a systematic change between "hotter" and "cooler" zones along the major direction of fluid flow inferred for the \#2 orebody (Logan et al., 2001), but Williford et al. (2011) could not find a clear geographical trend in aromatic ratios in samples from the \#5 orebody, which they suggested could be consequence of a more easterly source of fluids (Ireland et al., 2004).

The values of $T_{\text {app }}$ shown in Fig. 6c calculated using data from Chen et al. (2003) show an increase 
with proximity to the fault zone in accord with the hypothesis of Chen et al. (2003) that these samples were exposed to hotter conditions. We interpret this increase in $T_{\text {app }}$ to represent a signal of metastable equilibration, indicated by the arrow in Fig. 6c. Notably, the highest values of $T_{\text {app }}$ shown in Fig. $6 \mathrm{c}$ are less than $200^{\circ} \mathrm{C}$ (for both MPI-3 and MPR; the points plot at the nearly same $T_{\text {app}}$ ), which are lower than the temperatures proposed by Chen et al. (2003) and Logan et al. (2001), so the values may reflect a shift to equilibrium at lower temperatures than those found in the deepest parts of the hydrothermal system. In contrast, the values of $T_{\text {app }}$ shown in Fig. 6d, calculated using data from Williford et al. (2011), meet neither of the criteria for equilibrium. Compared to other plots in the figure, the $T_{\text {app }}$ between MPR and MPI-3 for the data from Williford et al. (2011) shown in Fig. 6d do not exhibit a systematic convergence, and there is no obvious increase in $T_{\text {app }}$ in proximity to the fault zone that is the presumed source of the fluids.

If any possible isomeric equilibration between the PAHs occurred, it would be more likely at the higher temperatures deeper in the hydrothermal system, not in the depositional environment of the orebody proper, where hydrothermal fluids would mix with either open ocean or dominantly cooler seawater-derived fluid in the pores. Therefore, the trends in relative abundances of isomers reported by both Chen et al. (2003) and Williford et al. (2011) may be controlled to a greater extent by fluid source at depth and discharge patterns, instead of an actual thermal gradient located within the present location of the orebody relative to the Emu fault zone. Nevertheless, the values of MPR and MPI-3 reported by Williford et al. (2011) are significantly lower than those of Chen et al. (2003), which can be explained using the conventional kinetically controlled model for maturation at a lower maturity in the samples of Williford et al. (2011). This outcome is also consistent with the deuterium isotope results reported by Williford et al. (2011) that are indicative of exchange with a brine.

\subsection{Use of MPR as a geothermometer}

MPR is sensitive to temperature (Fig. 4b) so it is possible to use this parameter as a geothermometer. Temperature estimates are challenging in low grade metamorphic rocks such as those in which MPR ratios might be measured. Existing geothermometers, such as the illite crystallinity index, are notoriously sensitive to kinetic effects and other factors such as crystal size, strain, sample preparation and calibration methods (e.g. Roberts et al., 1991; Bertrand et al., 1998; Mählmann and Frey, 2012). While kinetic effects have to be carefully assessed for MPR, it is possible to assess the proximity to equilibrium via comparison of the different ratios as described above, and the kinetics of MP isomerization reactions are likely to be more rapid than for recrystallization of a solid phase such as illite, which favors the use of this parameter in geothermometry. However, the relatively wide error bars in Fig. $4 \mathrm{~b}$, and the restricted 
data set from which the thermodynamic parameters are drawn, mean that while this initial calibration of the MP geothermometer may be relatively robust in relative terms, absolute temperature values should be treated with caution and further testing is required. Nevertheless, MPR measurements seem likely to provide a promising addition to our arsenal of geothermometers.

\subsection{Equilibrium values of MPI-1 in temperature and redox space}

The definition of MPI-1 (Eq. 3) includes abundances of P and MPs, for which the average oxidation states of carbon are -0.71 and -0.8 , respectively. Because of these differences, the value of MPI- 1 at metastable equilibrium is sensitive to changes in oxidation-reduction conditions, not only temperature. In early studies, the correlation between MPI-1 and vitrinite reflectance was found to reverse at high $R_{O}$ (Radke et al., 1982a; Radke and Welte, 1983). Arouri et al. (2000) found values of MPI-1 in solvent extracts of acritarch-rich rock samples that were lower than expected for the high maturities deduced from spectroscopic (laser Raman) observations (estimated paleotemperature of about $230{ }^{\circ} \mathrm{C}$ ). Other field observations indicate that redox conditions as well as temperature exert an influence on MPI-1. For example, MPI-1 was also observed to decrease with a shift from reducing to oxidizing conditions in the Kupferschiefer (Püttmann et al., 1989; Sun, 1998; Bechtel et al., 2001). To quantify this sensitivity, we calculate metastable equilibrium values of MPI- 1 as a function of both the activity of hydrogen $\left(a_{\mathrm{H}_{2(a q)}}\right)$ and temperature, sharing features with a previously proposed model for metastable equilibrium between alkanes and alkenes by Shock (2000).

The overall conversion between $\mathrm{P}$ and MP, which may be a result of their preferential formation or destruction, is a redox-sensitive process. An overall reaction between P and MP conserving carbon can be written as

$$
15 \mathrm{C}_{14} \mathrm{H}_{10(\mathrm{P})}+9 \mathrm{H}_{2(a q)} \rightleftharpoons 14 \mathrm{C}_{15} \mathrm{H}_{12(\mathrm{MP})} .
$$

This reaction is analogous to one written by Zolotov and Shock (1999) to assess the relative stabilities of naphthalene and methylnaphthalene. As noted by those authors, the reaction written in this way does not represent any mechanism. Reaction 18 represents mass balance, based on the stoichiometric differences of the species, and specifically does not carry any implications regarding mechanisms and rates of conversion, formation or destruction of the species.

Equilibrium values of MPI- 1 calculated as a function of $\log a_{\mathrm{H}_{2(a q)}}$ and temperature are shown in Fig. 7. At a constant temperature, increasing $\log a_{\mathrm{H}_{2(a q)}}$ favors formation of MP, which has a lower oxidation state of carbon (is more reduced) than P, thereby increasing the equilibrium value of MPI-1. This finding is consistent with the proposal (Szczerba and Rospondek, 2010) that more oxidizing conditions might explain the decrease in MPI-1 at high maturities originally identified by Radke et al. (1982a) and Radke 
and Welte (1983). The calculated values of MPI-1 shown in Fig. 7 are similar to observed values for geologically reasonable ranges of temperature and $\log a_{\mathrm{H}_{2(a q)}}$. For example, tracking the values of $\log a_{\mathrm{H}_{2(a q)}}$ along the hematite-magnetite buffer line shown in Fig. 7, the metastable equilibrium values of MPI-1 decrease from 2 to 1 at ca. 170 to $310{ }^{\circ} \mathrm{C}$. These values of MPI- 1 are in the range known to occur in highly matured samples (Radke et al., 1982a).

\subsection{Comparison of ore and non-ore samples in temperature and redox space}

Consideration of the results of the equilibrium calculations described above suggests that it may be possible to use MPR and MPI-1 as proxies for temperature and redox conditions in hydrothermally altered systems. These proxies are interesting especially for assessing the probable conditions of fluids involved in formation of ore deposits, as the proxies may provide information on apparent temperatures and redox conditions in samples from mineralized and non-mineralized locations. Values of MPI-1 and MPR taken from the literature are shown in Fig. 8a for samples already assessed as having some imprint of equilibration, i.e. those represented by filled symbols in Fig. 6. The points shown in Fig. 8a using data from Brocks et al. (2003a) for the Hamersley Group are those for which values of $T_{\text {app }}$ calculated from MPR and MPI-3 differ by less than $50{ }^{\circ} \mathrm{C}$ (samples Rae6, Mam2, Mam1). In this figure it can be seen that the ore-system samples have higher values of MPI-1 than the unmineralized samples. Because of the low coverage of available data, is difficult to establish the generality of pattern of a higher MPI-1 in sulfide ore deposits than in non-mineralized, but heated sediments.

We calculated values of temperature and $\log a_{\mathrm{H}_{2}}$, shown in Fig. $8 \mathrm{~b}$, that would characterize the system if the values of MPR and MPI-1 shown in Fig. 8a were equilibrium values. First, MPR, which is not redox-sensitive, was converted to an equilibrium value of temperature using the curve shown in Fig. 4b. The values of calculated temperature and reported MPI-1 were combined with the contours shown in Fig. 7 to derive values of $\log a_{\mathrm{H}_{2}}$ that are shown in Fig. 8b. Comparisons between these values of $T$ and $\log a_{\mathrm{H}_{2}}$ with the sulfide-sulfate system or other inorganic redox reactions may be used to assess possible buffering effects or other interactions between organic and inorganic species. The curve in Fig. $8 \mathrm{~b}$ was calculated from the law of mass action for

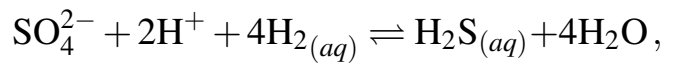

which can be written as

$$
\log K=\log \frac{a_{\mathrm{H}_{2} \mathrm{~S}_{(a q)}}}{a_{\mathrm{SO}_{4}^{2-}}}+4 \log a_{\mathrm{H}_{2} \mathrm{O}}-4 \log a_{\mathrm{H}_{2(a q)}}-2 \log a_{\mathrm{H}^{+}}
$$

Values of $\log K$ for Reaction 19 were calculated using CHNOSZ (Dick, 2008); standard molal thermo- 
dynamic properties and equations of state parameters for $\mathrm{SO}_{4}^{2-}$ were taken from Shock and Helgeson (1988), and those for $\mathrm{H}_{2} \mathrm{~S}_{(a q)}$ were taken from Shock et al. (1989) and Schulte et al. (2001). The line in Fig. $8 \mathrm{~b}$ corresponds to values of $\log a_{\mathrm{H}_{2(a q)}}$ calculated using $a_{\mathrm{H}_{2} \mathrm{~S}}=a_{\mathrm{SO}_{4}^{2-}}, a_{\mathrm{H}_{2} \mathrm{O}}=1$ and $\mathrm{pH}$ of neutrality, i.e. $\mathrm{pH}=-\log a_{\mathrm{H}^{+}}=-\log K_{21} / 2$ where $\log K_{21}$ refers to the following reaction:

$$
\mathrm{H}_{2} \mathrm{O} \rightleftharpoons \mathrm{H}^{+}+\mathrm{OH}^{-}
$$

At temperatures greater than $\sim 50{ }^{\circ} \mathrm{C}$, the $\mathrm{pH}$ of neutrality is such that $\mathrm{H}_{2} \mathrm{~S}$ forms to a greater extent than $\mathrm{HS}^{-}$, which is why the former was used in writing Reaction 19. At neutral $\mathrm{pH}$ at temperatures above $295^{\circ} \mathrm{C}, \mathrm{HSO}_{4}^{-}$becomes more dominant than $\mathrm{SO}_{4}^{2-}$; this shift in speciation would be apparent as a small counterclockwise rotation of the line shown in Fig. 8b, such that the line would pass through the lower of the two high-temperature points.

It can be seen in Fig. 8b that the values of temperature and $\log a_{\mathrm{H}_{2(a q)}}$ inferred by interpreting the measured MPR and MPI-1 as ratios at metastable equilibrium fall on both sides of the equal-activity line between $\mathrm{SO}_{4}^{2-}$ and $\mathrm{H}_{2} \mathrm{~S}$. It follows that the relatively high values of MPI-1 found in the ore-derived samples (Chen et al., 2003) and high-maturity source rocks (George and Ahmed, 2002) considered here may be used as proxies for reducing conditions, consistent with the potential for sulfidization. In contrast, more oxidizing conditions are suggested by the metastable equilibrium interpretation of maturity ratios in organic matter found closest to an igneous intrusion (George, 1992) and in one of the heated Archean samples (Brocks et al., 2003a). Two of the samples with data reported by Brocks et al. (2003a) are plotted in Fig. $8 \mathrm{~b}$ at ca. $350-360^{\circ} \mathrm{C}$ and relatively reducing conditions. These temperatures are higher than the range of metamorphic temperatures discussed by Brocks et al. (2003a). As noted above, the retrieval of absolute temperatures may not be possible; a temperature difference of $50{ }^{\circ} \mathrm{C}$ is within the uncertainties associated with the thermodynamic derivations, and other factors, such as the difference between aqueous and solid-phase properties (see Fig. 4) should also be considered.

To summarize, there is an apparent trend toward more reducing conditions for the ore-derived and high-maturity source-rock samples compared to samples affected by local heating due to igneous activity or regional low-grade metamorphism. For the ore system, these findings are consistent with a scenario in which hydrothermal fluids are either carriers of the aromatic compounds or simply in contact with them. If the fluids were carriers of aromatic compounds, then the fluids most likely contained reduced sulfur species rather than sulfate. If, on the other hand, the moving fluids reacted with organic matter that was already in place, the source of reducing equivalents could be inorganic, such as previously deposited pyrite or other sulfides. 


\section{Conclusions}

This study was motivated by reported observations that values of the methylphenanthrene ratio 2MP/1-MP (MPR) reverse in high-maturity source rocks at temperatures higher than the oil window $\left(>130{ }^{\circ} \mathrm{C}\right)$, and some values are found that are lower than expected in metamorphosed Archean shales (estimated temperatures $\sim 250-300{ }^{\circ} \mathrm{C}$ ) and in igneous and hydrothermal systems. Data available in the literature for the equilibrium constant of the reaction between aqueous $1-\mathrm{MP} \rightleftharpoons 2-\mathrm{MP}$ are available only at $25^{\circ} \mathrm{C}$. In this study, we estimated a set of standard molal thermodynamic properties $\left(\Delta G_{f}^{\circ}, \Delta H_{f}^{\circ}\right.$, $\left.S^{\circ}, C_{P}^{\circ}, V^{\circ}\right)$ at $25^{\circ} \mathrm{C}$ in order to generate provisional estimates of the standard Gibbs energies of $\mathrm{P}$ and isomers of MP to $\sim 500{ }^{\circ} \mathrm{C}$. The calculated equilibrium constant of the reaction 1-MP $\rightleftharpoons 2$-MP decreases significantly with increasing temperature. Therefore, the stability difference between the $\alpha$ - and $\beta$ isomers becomes smaller at higher temperatures, eventually so that the $\alpha$ isomer becomes more stable. Quantifying this behavior enables the use of MPR and related maturity indicators as geothermometers; however, error propagation analysis suggests that this is best used as a tool to recognize relative temperatures (i.e. geothermal gradients) rather than as a measure of absolute temperature. Based on these findings, reports in the literature of reversals of some aromatic maturity ratios at high temperature are not anomalies, but instead are expected outcomes of the onset of metastable equilibration of the system with increasing temperature.

Metastable equilibrium will only be reached in systems that are old enough, and/or have been heated sufficiently that $\mathrm{P}$ and MP abundances approach an equilibrium distribution. Comparison of apparent temperatures of metastable equilibrium in samples revealed a number of samples that have a plausible metastable equilibrium signature. $\mathrm{P}$ and isomers of MP can also be used as organic tracers also of redox conditions. High MPI-1 values for organic compounds associated with ore deposits and a deep hydrocarbon exploration well, but not intrusive or metamorphosed samples, indicate redox conditions toward the reducing (sulfide) side of the sulfide-sulfate stability boundary. The metastable equilibrium constraints do not imply any specific mechanisms, but are compatible with, and place constraints on, the probable products of reaction mechanisms that include preferential degradation or isomerization through structural rearrangements. Fluid flow and migration can dramatically alter the observed maturity parameters, so inferences based on the metastable equilibrium model must be made in the context of these processes. 


\section{Acknowledgements}

We thank Lorenz Schwark and two reviewers for comments that helped to improve this manuscript. This research was supported by the CSIRO Minerals Down Under Flagship Cluster, "Organic Geochemistry of Mineral Systems". Approval to publish was given by the Cluster Management Committee; the funders had no role in study design, collection, analysis and interpretation of data, or writing of the report. 


\section{References}

Alexander, R., Bastow, T. P., Fisher, S. J., Kagi, R. I., 1995. Geosynthesis of organic compounds: II. Methylation of phenanthrene and alkylphenanthrenes. Geochim. Cosmochim. Acta 59 (20), 42594266.

Amidon, G. L., Anik, S. T., 1980. Hydrophobicity of Polycyclic Aromatic Compounds. Thermodynamic Partitioning Analysis. J. Phys. Chem. 84 (9), 970-974.

Anderson, G. M., Crerar, D. A., 1993. Thermodynamics in Geochemistry: The Equilibrium Model. Oxford University Press.

Arouri, K. R., Greenwood, P. F., Walter, M. R., 2000. Biological affinities of Neoproterozoic acritarchs from Australia: microscopic and chemical characterisation. Org. Geochem. 31 (1), 75-89.

Bastow, T. P., Alexander, R., Fisher, S. J., Singh, R. K., van Aarssen, B. G. K., Kagi, R. I., 2000. Geosynthesis of organic compounds. Part V - methylation of alkylnaphthalenes. Org. Geochem. 31 (6), 523534.

Bechtel, A., Gratzer, R., Püttmann, W., Oszczepalski, S., 2001. Variable alteration of organic matter in relation to metal zoning at the Rote Fäule front (Lubin-Sieroszowice mining district, SW Poland). Org. Geochem. 32 (3), 377-395.

Bechtel, A., Püttmann, W., Hoernes, S., 1995. Reconstruction of the thermal history of the Kupferschiefer within the Zechstein basin of Central Europe: A stable isotope and organic geochemical approach. Ore Geol. Rev. 9 (5), 371-389.

Bertrand, R., Chagnon, A., Héroux, Y., Savard, M. M., 1998. Hydrothermal alteration of clay minerals and organic matter within and outside the Jubilee carbonate-hosted $\mathrm{Zn}-\mathrm{Pb}$ deposit, Cape Breton Island, Nova Scotia, Canada. Econ. Geol. 93 (6), 746-756.

Bishop, A. N., Abbott, G. D., 1993. The interrelationship of biological marker maturity parameters and molecular yields during contact metamorphism. Geochim. Cosmochim. Acta 57 (15), 3661-3668.

Bishop, A. N., Abbott, G. D., 1995. Vitrinite reflectance and molecular geochemistry of Jurassic sediments: the influence of heating by Tertiary dykes (northwest Scotland). Org. Geochem. 22 (1), 165177. 
Boreham, C. J., Crick, I. H., Powell, T. G., 1988. Alternative calibration of the methylphenanthrene index against vitrinite reflectance: Application to maturity measurements on oils and sediments. Org. Geochem. 12 (3), 289-294.

Brocks, J. J., 2011. Millimeter-scale concentration gradients of hydrocarbons in Archean shales: Live-oil escape or fingerprint of contamination? Geochim. Cosmochim. Acta 75 (11), 3196-3213.

Brocks, J. J., Buick, R., Logan, G. A., Summons, R. E., 2003a. Composition and syngeneity of molecular fossils from the 2.78 to 2.45 billion-year-old Mount Bruce Supergroup, Pilbara Craton, Western Australia. Geochim. Cosmochim. Acta 67 (22), 4289-4319.

Brocks, J. J., Summons, R. E., Buick, R., Logan, G. A., 2003b. Origin and significance of aromatic hydrocarbons in giant iron ore deposits of the late Archean Hamersley Basin, Western Australia. Org. Geochem. 34 (8), 1161-1175.

Budzinski, H., Garrigues, P., Radke, M., Connan, J., Oudin, J.-L., 1993. Thermodynamic calculations on alkylated phenanthrenes: geochemical applications to maturity and origin of hydrocarbons. Org. Geochem. 20 (7), 917-926.

Burkitt, F. H., Coulson, C. A., Longuet-Higgins, H. C., 1951. Free valence in unsaturated hydrocarbons. Trans. Faraday Soc. 47, 553-564.

Charlesworth, J. M., 1987. Thermodynamic modeling of oil shale pyrolysis. Energy Fuels 1 (6), 488496.

Chen, J., Walter, M. R., Logan, G. A., Hinman, M. C., Summons, R. E., 2003. The Paleoproterozoic McArthur River (HYC) Pb/Zn/Ag deposit of northern Australia: organic geochemistry and ore genesis. Earth Planet. Sci. Lett. 210 (3-4), 467-479.

Chirico, R. D., Hossenlopp, I. A., Nguyen, A., Steele, W. V., Gammon, B. E., 1989. The thermodynamic properties of 4-methylphenanthrene. J. Chem. Thermodyn. 21 (2), 179-201.

Clarke, E. C. W., Glew, D. N., 1966. Evaluation of thermodynamic functions from equilibrium constants. Trans. Faraday Soc. 62, $539-547$.

Coleman, D. J., Pilcher, G., 1966. Heats of combustion of biphenyl, bibenzyl, naphthalene, anthracene and phenanthrene. Trans. Faraday Soc. 62, 821-827. 
Cox, J. D., Wagman, D. D., Medvedev, V. A. (Eds.), 1989. CODATA Key Values for Thermodynamics. Hemisphere Publishing Corporation, New York.

URL http://www . worldcat.org/oclc/18559968

Davies, C. P. N., 1997. Unusual biomarker maturation ratio changes through the oil window, a consequence of varied thermal history. Org. Geochem. 27 (7-8), 537-560.

Dick, J. M., 2008. Calculation of the relative metastabilities of proteins using the CHNOSZ software package. Geochem. Trans. 9, 10.

Dolfing, J., Xu, A., Gray, N. D., Larter, S. R., Head, I. M., 2009. The thermodynamic landscape of methanogenic PAH degradation. Microb. Biotechnol. 2 (5), 566-574.

Dow, W. G., 1977. Kerogen studies and geological interpretations. J. Geochem. Explor. 7 (2), 79-99.

Finke, H. L., Messerly, J. F., Lee, S. H., Osborn, A. G., Douslin, D. R., 1977. Comprehensive thermodynamic studies of seven aromatic hydrocarbons. J. Chem. Thermodyn. 9 (10), 937-956.

Fusetti, L., Behar, F., Bounaceur, R., Marquaire, P.-M., Grice, K., Derenne, S., 2010a. New insights into secondary gas generation from the thermal cracking of oil: Methylated monoaromatics. A kinetic approach using 1,2,4-trimethylbenzene. Part I: A mechanistic kinetic model. Org. Geochem. 41 (2), $146-167$.

Fusetti, L., Behar, F., Grice, K., Derenne, S., 2010b. New insights into secondary gas generation from the thermal cracking of oil: Methylated mono-aromatics. A kinetic approach using 1,2,4trimethylbenzene. Part II: An empirical kinetic model. Org. Geochem. 41 (2), 168-176.

Garrigues, P., De Sury, R., Angelin, M. L., Bellocq, J., Oudin, J. L., Ewald, M., 1988. Relation of the methylated aromatic hydrocarbon distribution pattern to the maturity of organic-matter in ancient sediments from the Mahakam delta. Geochim. Cosmochim. Acta 52 (2), 375-384.

Garrigues, P., Ewald, M., 1983. Natural occurrence of 4-methyl-phenanthrene in petroleums and recent marine sediments: A new sensitive method to identify and quantify isomers in a series of alkyl-PAH: High resolution spectrofluorimetry at $15 \mathrm{~K}$ in $n$-alkane (Shpolskii effect). Org. Geochem. 5 (2), 53-56.

Garrigues, P., Oudin, J. L., Parlanti, E., Monin, J. C., Robcis, S., Bellocq, J., 1990. Alkylated phenanthrene distribution in artificially matured kerogens from Kimmeridge clay and the Brent Formation (North Sea). Org. Geochem. 16 (1-3), 167-173. 
George, S. C., 1992. Effect of igneous intrusion on the organic geochemistry of a siltstone and an oil shale horizon in the Midland Valley of Scotland. Org. Geochem. 18 (5), 705-723.

George, S. C., Ahmed, M., 2002. Use of aromatic compound distributions to evaluate organic maturity of the Proterozoic middle Velkerri Formation, McArthur Basin, Australia. In: Keep, M., Moss, S. (Eds.), The Sedimentary Basins of Western Australia. Vol. 3 of Proceedings of the Petroleum Exploration Society of Australia Symposium. Perth, WA, pp. 253-270.

Giże, A. P., Kuehn, C. A., Furlong, K. P., Gaunt, J. M., 2000. Organic maturation modeling applied to ore genesis and exploration. In: Reviews in Economic Geology. Vol. 9. Society of Economic Geologists, pp. 87-104.

Greenwood, P. F., Brocks, J. J., Grice, K., Schwark, L., Jaraula, C. M. B., Dick, J. M., Evans, K. A., 2013. Organic geochemistry and mineralogy. I. Characterization of organic matter associated with metal deposits. Ore Geol. Rev. 50, 1-27.

Helgeson, H. C., Kirkham, D. H., Flowers, G. C., 1981. Theoretical prediction of the thermodynamic behavior of aqueous electrolytes at high pressures and temperatures: IV. Calculation of activity coefficients, osmotic coefficients, and apparent molal and standard and relative partial molal properties to $600^{\circ} \mathrm{C}$ and $5 \mathrm{~Kb}$. Am. J. Sci. 281 (10), 1249-1516.

Helgeson, H. C., Knox, A. M., Owens, C. E., Shock, E. L., 1993. Petroleum, oil-field waters, and authigenic mineral assemblages: Are they in metastable equilibrium in hydrocarbon reservoirs? Geochim. Cosmochim. Acta 57 (14), $3295-3339$.

Helgeson, H. C., Owens, C. E., Knox, A. M., Richard, L., 1998. Calculation of the standard molal thermodynamic properties of crystalline, liquid, and gas organic molecules at high temperatures and pressures. Geochim. Cosmochim. Acta 62 (6), $985-1081$.

Helgeson, H. C., Richard, L., McKenzie, W. F., Norton, D. L., Schmitt, A., 2009. A chemical and thermodynamic model of oil generation in hydrocarbon source rocks. Geochim. Cosmochim. Acta 73 (3), 594-695.

Holloway, J. R., 1984. Graphite- $\mathrm{CH}_{4}-\mathrm{H}_{2} \mathrm{O}-\mathrm{CO}_{2}$ equilibria at low-grade metamorphic conditions. Geology $12(8), 455-458$. 
Holman, A. I., Grice, K., Jaraula, C. M. B., Schimmelmann, A., Brocks, J. J., 2012. Efficiency of extraction of polycyclic aromatic hydrocarbons from the Paleoproterozoic Here's Your Chance $\mathrm{Pb} / \mathrm{Zn} / \mathrm{Ag}$ ore deposit and implications for a study of Bitumen II. Org. Geochem. 52 (0), 81-87.

Hunt, J. M., 1996. Petroleum Geochemistry and Geology, 2nd Edition. W. H. Freeman, New York.

Ireland, T., Bull, S. W., Large, R. R., 2004. Mass flow sedimentology within the HYC Zn-Pb-Ag deposit, Northern Territory, Australia: evidence for syn-sedimentary ore genesis. Miner. Deposita 39 (2), 143158.

Isnard, P., Lambert, S., 1989. Aqueous solubility and n-octanol/water partition coefficient correlations. Chemosphere 18 (9-10), 1837-1853.

Johnson, J. W., Oelkers, E. H., Helgeson, H. C., 1992. SUPCRT92: A software package for calculating the standard molal thermodynamic properties of minerals, gases, aqueous species, and reactions from 1 to 5000 bar and 0 to $1000^{\circ}$ C. Comp. Geosci. 18 (7), $899-947$.

Karásek, P., Planeta, J., Roth, M., 2007. Aqueous solubility data for pressurized hot water extraction for solid heterocyclic analogs of anthracene, phenanthrene and fluorene. J. Chromatogr. A 1140 (1-2), 195-204.

Karr, Jr., C., Estep, P. A., Lo Chang, T.-C., Comberiati, J. R., 1967. Identification of Distillable Paraffins, Olefins, Aromatic Hydrocarbons, and Neutral Heterocycles from a Low-Temperature Bituminous Coal Tar. U. S. Bureau of Mines.

Kawka, O. E., Simoneit, B. R. T., 1990. Polycyclic aromatic hydrocarbons in hydrothermal petroleums from the Guaymas Basin spreading center. Appl. Geochem. 5 (1-2), 17-27.

Kawka, O. E., Simoneit, B. R. T., 1994. Hydrothermal pyrolysis of organic matter in Guaymas Basin: I. Comparison of hydrocarbon distributions in subsurface sediments and seabed petroleums. Org. Geochem. 22 (6), 947-978.

Kolaczkowska, E., Slougui, N.-E., Watt, D. S., Maruca, R. E., Moldowan, J. M., 1990. Thermodynamic stability of various alkylated, dealkylated and rearranged $17 \alpha$ - and $17 \beta$-hopane isomers using molecular mechanics calculations. Org. Geochem. 16 (4-6), 1033-1038.

Konn, C., Charlou, J.-L., Donval, J.-P., Holm, N. G., 2012. Characterisation of dissolved organic compounds in hydrothermal fluids by stir bar sorptive extraction - gas chomatography - mass spectrometry. Case study: the Rainbow field ( $36^{\circ} \mathrm{N}$, Mid-Atlantic Ridge). Geochem. Trans. 13, 8 . 
Kvalheim, O. M., Christy, A. A., Telnæs, N., Bjørseth, A., 1987. Maturity determination of organic matter in coals using the methylphenanthrene distribution. Geochim. Cosmochim. Acta 51 (7), 18831888.

Large, R. R., Bull, S. W., Cooke, D. R., McGoldrick, P. J., 1998. A genetic model for the HYC deposit, Australia: Based on regional sedimentology, geochemistry, and sulfide-sediment relationships. Econ. Geol. 93 (8), 1345-1368.

Levelt-Sengers, J. M. H., Kamgar-Parsi, B., Balfour, F. W., Sengers, J. V., 1983. Thermodynamic properties of steam in the critical region. J. Phys. Chem. Ref. Data 12 (1), $1-28$.

Logan, G. A., Hinman, M. C., Walter, M. R., Summons, R. E., 2001. Biogeochemistry of the 1640 Ma McArthur River (HYC) lead-zinc ore and host sediments, Northern Territory, Australia. Geochim. Cosmochim. Acta 65 (14), 2317-2336.

Love, G. D., Snape, C. E., Carr, A. D., Houghton, R. C., 1996. Changes in molecular biomarker and bulk carbon skeletal parameters of vitrinite concentrates as a function of rank. Energy Fuels 10 (1), $149-157$.

Mackay, D., Shiu, W. Y., 1977. Aqueous solubility of polynuclear aromatic hydrocarbons. J. Chem. Eng. Data 22 (4), 399-402.

Mackenzie, A. S., 1984. Applications of biological markers in petroleum geochemistry. In: Brooks, J., Welte, D. (Eds.), Advances in Petroleum Geochemistry. Vol. 1. Academic Press, London, pp. 115214.

Mackenzie, K. L., Marshall, C. P., Walter, M. R., 2008. Regional organic geochemistry of host sediments of Palaeoproterozoic McArthur River ore deposit, Australia. Theor. Chem. Acc. 119 (1-3), 143-153.

Mählmann, R. F., Frey, M., 2012. Standardisation, calibration and correlation of the Kübler-index and the vitrinite/bituminite reflectance: an inter-laboratory and field related study. Swiss J. Geosci. 105 (2), $153-170$.

Maier, C. G., Kelley, K. K., 1932. An equation for the representation of high-temperature heat content data. J. Am. Chem. Soc. 54 (8), 3243 - 3246.

May, W. E., Wasik, S. P., Freeman, D. H., 1978. Determination of the solubility behavior of some polycyclic aromatic hydrocarbons in water. Anal. Chem. 50 (7), 997-1000. 
May, W. E., Wasik, S. P., Miller, M. M., Tewari, Y. B., Brown-Thomas, J. M., Goldberg, R. N., 1983. Solution thermodynamics of some slightly soluble hydrocarbons in water. J. Chem. Eng. Data 28 (2), 197-200.

McCollom, T. M., Seewald, J. S., Simoneit, B. R. T., 2001. Reactivity of monocyclic aromatic compounds under hydrothermal conditions. Geochim. Cosmochim. Acta 65 (3), 455-468.

McCollom, T. M., Simoneit, B. R. T., Shock, E. L., 1999. Hydrous pyrolysis of polycyclic aromatic hydrocarbons and implications for the origin of PAH in hydrothermal petroleum. Energy Fuels 13 (2), 401-410.

Meylan, W. M., Howard, P. H., Boethling, R. S., 1996. Improved method for estimating water solubility from octanol/water partition coefficient. Environ. Toxicol. Chem. 15 (2), 100-106.

Nomoto, S., Hagiwara, M., Nakano, Y., Shimoyama, A., 2000. A new parameter for maturity determination of organic matter in sediments based on the clay-catalyzed thermal isomerization of monomethylphenanthrenes. Bull. Chem. Soc. Japan 73 (6), 1437-1443.

Othman, R., Arouri, K. R., Ward, C. R., McKirdy, D. M., 2001. Oil generation by igneous intrusions in the northern Gunnedah Basin, Australia. Org. Geochem. 32 (10), 1219-1232.

Peters, K. E., Walters, C. C., Moldowan, J. M., 2005. The Biomarker Guide, 2nd Edition. Vol. 2, Biomarkers and Isotopes in Petroleum Exploration and Earth History. Cambridge University Press.

Philippi, G. T., 1974. The influence of marine and terrestrial source material on composition of petroleum. Geochim. Cosmochim. Acta 38 (6), 947 - 966.

Plyasunov, A. V., Shock, E. L., 2001. Correlation strategy for determining the parameters of the revised Helgeson-Kirkham-Flowers model for aqueous nonelectrolytes. Geochim. Cosmochim. Acta 65, 3879 -3900 .

Price, L. C., 1993. Thermal stability of hydrocarbons in nature: Limits, evidence, characteristics, and possible controls. Geochim. Cosmochim. Acta 57 (14), 3261 - 3280.

Püttmann, W., Merz, C., Speczik, S., 1989. The secondary oxidation of organic material and its influence on Kupferschiefer mineralization of southwest Poland. Appl. Geochem. 4 (2), 151-161. 
R Core Team, 2012. R: A Language and Environment for Statistical Computing. R Foundation for Statistical Computing, Vienna, Austria, ISBN 3-900051-07-0.

URL http://www.R-project.org

Radke, M., 1987. Organic geochemistry of aromatic hydrocarbons. In: Brooks, J., Welte, D. (Eds.), Advances in Petroleum Geochemistry. Vol. 2. Academic Press, London, pp. 141-207.

Radke, M., Welte, D., 1983. The methylphenanthrene index (MPI): A maturity parameter based on aromatic hydrocarbons. In: Bjøroy, M. (Ed.), Advances in Organic Geochemistry 1981. John Wiley and Sons Limited, pp. 504-512.

Radke, M., Welte, D. H., Willsch, H., 1982a. Geochemical study on a well in the Western Canada Basin: relation of the aromatic distribution pattern to maturity of organic matter. Geochim. Cosmochim. Acta $46(1), 1-10$.

Radke, M., Willsch, H., Leythaeuser, D., Teichmüller, M., 1982b. Aromatic components of coal: relation of distribution pattern to rank. Geochim. Cosmochim. Acta 46 (10), 1831-1848.

Raymond, A. C., Murchison, D. G., 1992. Effect of igneous activity on molecular-maturation indices in different types of organic matter. Org. Geochem. 18 (5), 725-735.

Richard, L., Helgeson, H. C., 1998. Calculation of the thermodynamic properties at elevated temperatures and pressures of saturated and aromatic high molecular weight solid and liquid hydrocarbons in kerogen, bitumen, petroleum, and other organic matter of biogeochemical interest. Geochim. Cosmochim. Acta 62, $3591-3636$.

Roberts, B., Merriman, R. J., Pratt, W., 1991. The influence of strain, lithology and stratigraphical depth on white mica (illite) crystallinity in mudrocks from the vicinity of the Corris Slate Belt, Wales: implications for the timing of metamorphism in the Welsh Basin. Geol. Mag. 128 (6), 633-645.

Rogoff, M. H., 1962. Chemistry of oxidation of polycyclic aromatic hydrocarbons by soil pseudomonads. J. Bacteriol. 83 (5), 998-1004.

URL http://www.ncbi.nlm.nih.gov/pmc/articles/PMC279399/

Sampei, Y., Shiomi, T., Ohira, H., 2004. Isomerization of methylphenanthrenes during catagenesis and metagenesis. J. Jpn. Assoc. Pet. Technol. 69 (2), 190-199.

URL http://sciencelinks.jp/j-east/article/200410/000020041004A0325580.php 
Sawamura, S., 2000. Pressure dependence of the solubilities of anthracene and phenanthrene in water at $25^{\circ}$ C. J. Solution Chem. 29 (4), 369-375.

Schulte, M. D., Shock, E. L., Wood, R. H., 2001. The temperature dependence of the standard-state thermodynamic properties of aqueous nonelectrolytes. Geochim. Cosmochim. Acta 65 (21), 39193930.

Schwab, V., Spangenberg, J. E., Grimalt, J. O., 2005. Chemical and carbon isotopic evolution of hydrocarbons during prograde metamorphism from $100^{\circ} \mathrm{C}$ to $550^{\circ} \mathrm{C}$ : Case study in the Liassic black shale formation of Central Swiss Alps. Geochim. Cosmochim. Acta 69 (7), 1825-1840.

Seewald, J. S., 2001. Aqueous geochemistry of low molecular weight hydrocarbons at elevated temperatures and pressures: Constraints from mineral buffered laboratory experiments. Geochim. Cosmochim. Acta 65 (10), 1641-1664.

Shock, E. L., 2000. Thermodynamic response of organic compounds in geochemical processes of sedimentary basins. In: Reviews in Economic Geology. Vol. 9. Society of Economic Geologists, pp. $105-117$.

Shock, E. L., Helgeson, H. C., 1988. Calculation of the thermodynamic and transport properties of aqueous species at high pressures and temperatures: Correlation algorithms for ionic species and equation of state predictions to $5 \mathrm{~kb}$ and $1000^{\circ} \mathrm{C}$. Geochim. Cosmochim. Acta 52 (8), 2009-2036.

Shock, E. L., Helgeson, H. C., 1990. Calculation of the thermodynamic and transport properties of aqueous species at high pressures and temperatures: Standard partial molal properties of organic species. Geochim. Cosmochim. Acta 54 (4), 915 - 945.

Shock, E. L., Helgeson, H. C., Sverjensky, D. A., 1989. Calculation of the thermodynamic and transport properties of aqueous species at high pressures and temperatures: Standard partial molal properties of inorganic neutral species. Geochim. Cosmochim. Acta 53 (9), 2157-2183.

Shock, E. L., Oelkers, E. H., Johnson, J. W., Sverjensky, D. A., Helgeson, H. C., 1992. Calculation of the thermodynamic properties of aqueous species at high pressures and temperatures: Effective electrostatic radii, dissociation constants, and standard partial molal properties to $1000{ }^{\circ} \mathrm{C}$ and $5 \mathrm{kbar}$. J. Chem. Soc., Faraday Trans. 88 (6), 803 - 826.

Simoneit, B. R. T., 2005. A review of current applications of mass spectrometry for biomarker/molecular tracer elucidations. Mass Spectrom. Rev. 24 (5), 719-765. 
Simoneit, B. R. T., Leif, R. N., Sturz, A. A., Sturdivant, A. E., Gieskes, J. M., 1992. Geochemistry of shallow sediments in Guaymas Basin, Gulf of California: hydrothermal gas and oil migration and effects of mineralogy. Org. Geochem. 18 (6), 765-784.

Smith, J. W., George, S. C., Batts, B. D., 1995. The geosynthesis of alkylaromatics. Org. Geochem. $23(1), 71-80$.

Strachan, M. G., Alexander, R., Subroto, E. A., Kagi, R. I., 1989. Constraints upon the use of 24ethylcholestane diastereomer ratios as indicators of the maturity of petroleum. Org. Geochem. 14 (4), 423-432.

Sun, Y.-Z., 1998. Influences of secondary oxidation and sulfide formation on several maturity parameters in Kupferschiefer. Org. Geochem. 29 (5-7), 1419-1429.

Sweeney, J. J., Burnham, A. K., 1990. Evaluation of a simple model of vitrinite reflectance based on chemical kinetics. AAPG Bull. 74 (10), 1559-1570.

Szczerba, M., Rospondek, M. J., 2010. Controls on distributions of methylphenanthrenes in sedimentary rock extracts: Critical evaluation of existing geochemical data from molecular modelling. Org. Geochem. 41 (12), 1297-1311.

Tanger, J. C. IV., Helgeson, H. C., 1988. Calculation of the thermodynamic and transport properties of aqueous species at high pressures and temperatures: Revised equations of state for the standard partial molal properties of ions and electrolytes. Am. J. Sci. 288 (1), 19-98.

Tissot, B. P., Welte, D. H., 1984. Petroleum Formation and Occurrence, 2nd Edition. Springer-Verlag, Berlin.

U.S. Environmental Protection Agency, 2011. EPI Suite - Estimation Software, version 4.10.

URL http://www.epa.gov/oppt/exposure/pubs/episuite.htm

van Duin, A. C. T., Baas, J. M. A., van de Graaf, B., de Leeuw, J. W., Bastow, T. P., Alexander, R., 1997. Comparison of calculated equilibrium mixtures of alkylnaphthalenes and alkylphenanthrenes with experimental and sedimentary data; the importance of entropy calculations. Org. Geochem. 26 (3-4), 275-280.

van Graas, G. W., 1990. Biomarker maturity parameters for high maturities: Calibration of the working range up to the oil/condensate threshold. Org. Geochem. 16 (4-6), 1025-1032. 
Ventura, G. T., Simoneit, B. R. T., Nelson, R. K., Reddy, C. M., 2012. The composition, origin and fate of complex mixtures in the maltene fractions of hydrothermal petroleum assessed by comprehensive two-dimensional gas chromatography. Org. Geochem. 45, 48-65.

Voigtmann, M. F., Yang, K., Batts, B. D., Smith, J. W., 1994. Evidence for synthetic generation of methylphenanthrenes in sediments. Fuel 73 (12), 1899-1903.

Wauchope, R. D., Getzen, F. W., 1972. Temperature dependence of solubilities in water and heats of fusion of solid aromatic hydrocarbons. J. Chem. Eng. Data 17 (1), 38-41.

Williford, K. H., Grice, K., Logan, G. A., Chen, J., Huston, D., 2011. The molecular and isotopic effects of hydrothermal alteration of organic matter in the Paleoproterozoic McArthur River $\mathrm{Pb} / \mathrm{Zn} / \mathrm{Ag}$ ore deposit. Earth Planet. Sci. Lett. 301 (1-2), 382-392.

Willsch, H., Radke, M., 1995. Distribution of polycyclic aromatic compounds in coals of high rank. Polycyclic Aromat. Compd. 7 (4), 231-251.

Wu, S.-H., Wang, Y.-S., Fan, L.-X., Robert, T. D. C., Huang, D.-S., 2002. Hydrous pyrolysis of methylphenanthrenes - Degradation and isomerization. J. Chin. Chem. Soc. 49 (3), 315-317.

Zolotov, M., Shock, E., 1999. Abiotic synthesis of polycyclic aromatic hydrocarbons on Mars. J. Geophys. Res. 104, 14033 - 14049. 


\section{1-methylphenanthrene}<smiles>Cc1cccc2c(N)cccc12</smiles><smiles>Cc1ccc2c(ccc3ccccc32)c1</smiles><smiles>C=Cc1ccc2c(P)c(C)ccc2c1</smiles><smiles>Cc1ccc2ccc3ccccc3c2c1</smiles>

Figure 1: Structures of the major compounds considered in this study and simplified depiction of reaction pathways during geosynthesis and maturation. The $\left[\mathrm{CH}_{2}\right]$ represents the difference in elemental stoichiometry between $\mathrm{P}$ and MP.

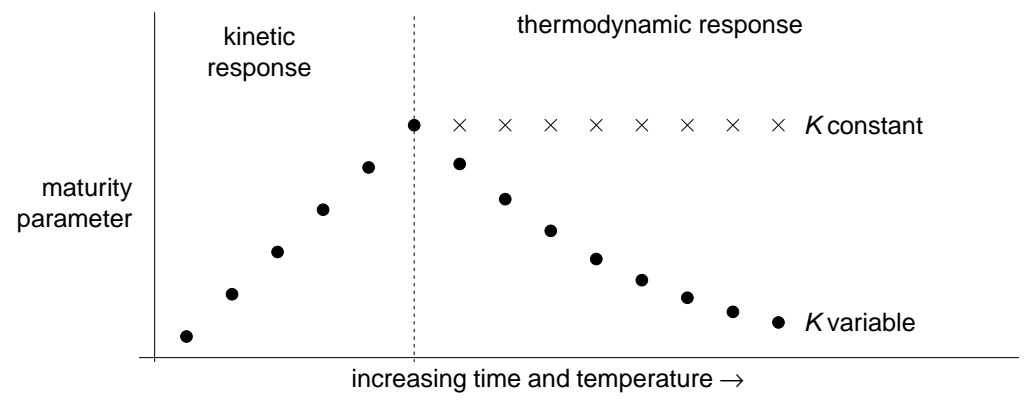

Figure 2: Generalized depiction of the change in an isomerization maturity parameter (MPR or MPI-3) with increasing time and temperature. The initial increase reflects a kinetic response as the reaction goes toward, but has not yet reached metastable equilibrium. A thermodynamic response at higher temperatures may cause a decrease in the maturity parameter as a result of a changing equilibrium constant. A constant value for the maturity parameter beyond the dashed vertical line would only be expected if the equilibrium constant(s) for the reaction(s) had no temperature dependence. 


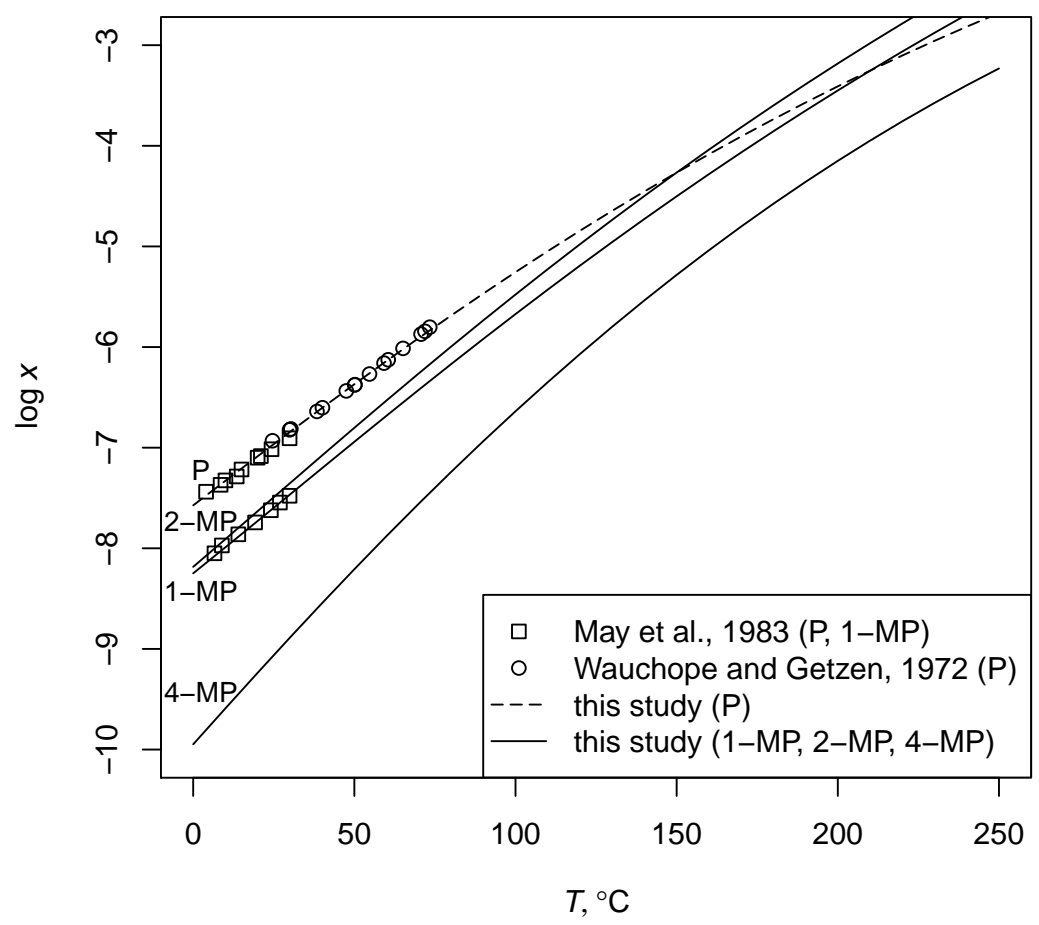

Figure 3: Temperature variation of solubility in mole fraction units for P, 1-MP, 2-MP and 4-MP, calculated by combining Eqs. (10) and (11) with the standard molal Gibbs energies of solution calculated from the difference between $\Delta G^{\circ}$ of the crystals using parameters from Richard and Helgeson (1998) and the aqueous species using the parameters listed in Table 1. Pressure is 1 bar below $100^{\circ} \mathrm{C}$ and the saturation vapor pressure of $\mathrm{H}_{2} \mathrm{O}\left(P_{\text {SAT }}\right)$ at higher temperatures. The symbols represent experimental data to $73{ }^{\circ} \mathrm{C}$ for $\mathrm{P}$ (Wauchope and Getzen, 1972) and to $30^{\circ} \mathrm{C}$ for $\mathrm{P}$ and 1-MP (May et al., 1983). 

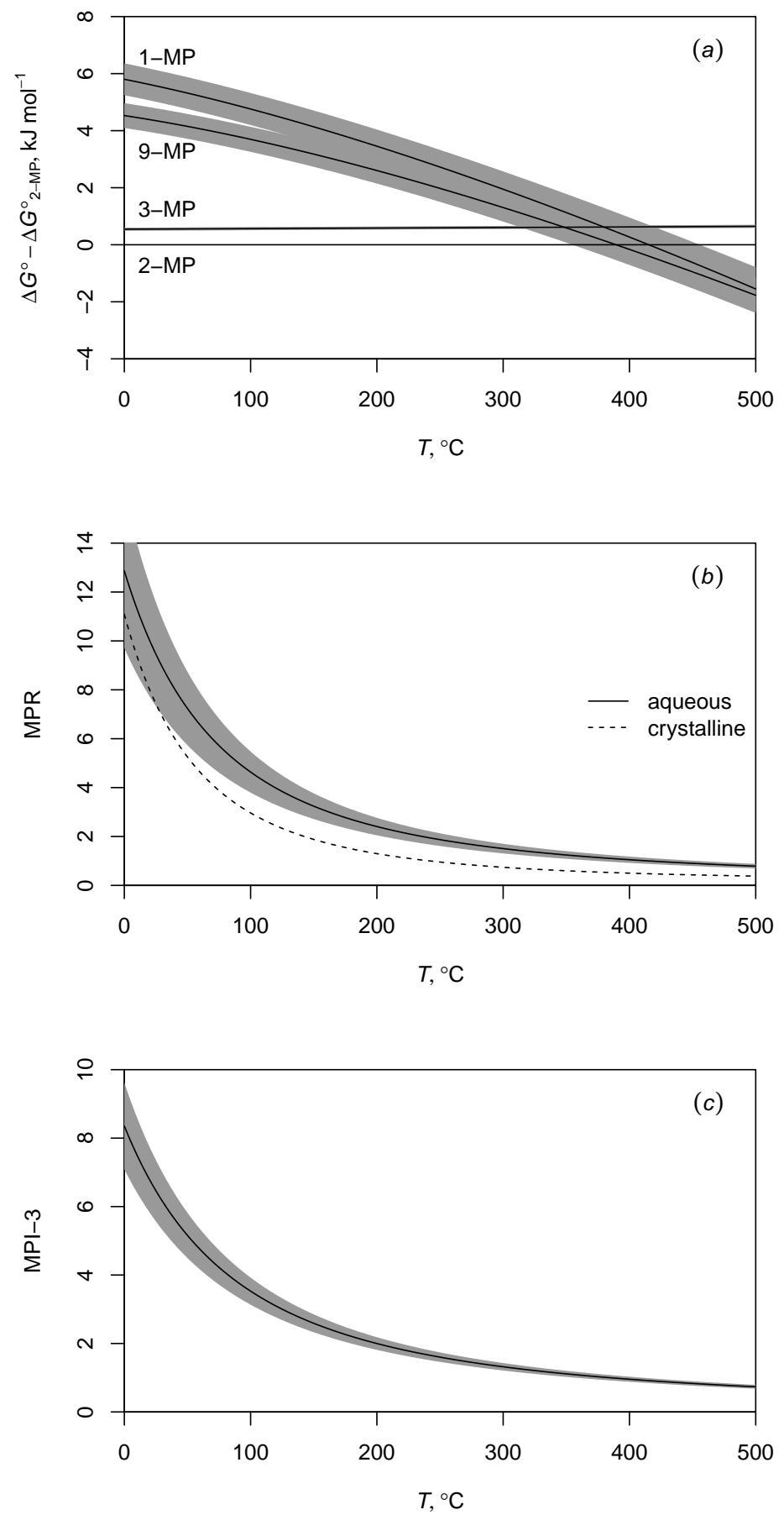

Figure 4: (a) Differences between calculated $\Delta G^{\circ}$ of aqueous 2-MP and other MP isomers as a function of temperature at 1000 bar. $\Delta G^{\circ}$ of 4-MP (not shown) is more than $35 \mathrm{~kJ} \mathrm{~mol}^{-1}$ higher than $\Delta G^{\circ}$ of 2-MP over the entire temperature range. (b) Values of the ratios MPR (Eq. 1) and (c) MPI-3 (Eq. 2) for metastable equilibrium among the aqueous MP isomers (solid lines) or crystalline isomers (dashed line). $\Delta G^{\circ}$ and metastable equilibrium distributions were calculated using the thermodynamic properties of the aqueous species given in Table 1 and of the crystalline compounds taken from Richard and Helgeson (1998). The shaded areas in each figure indicate the representative uncertainties in the derivation of the thermodynamic properties (see text). 


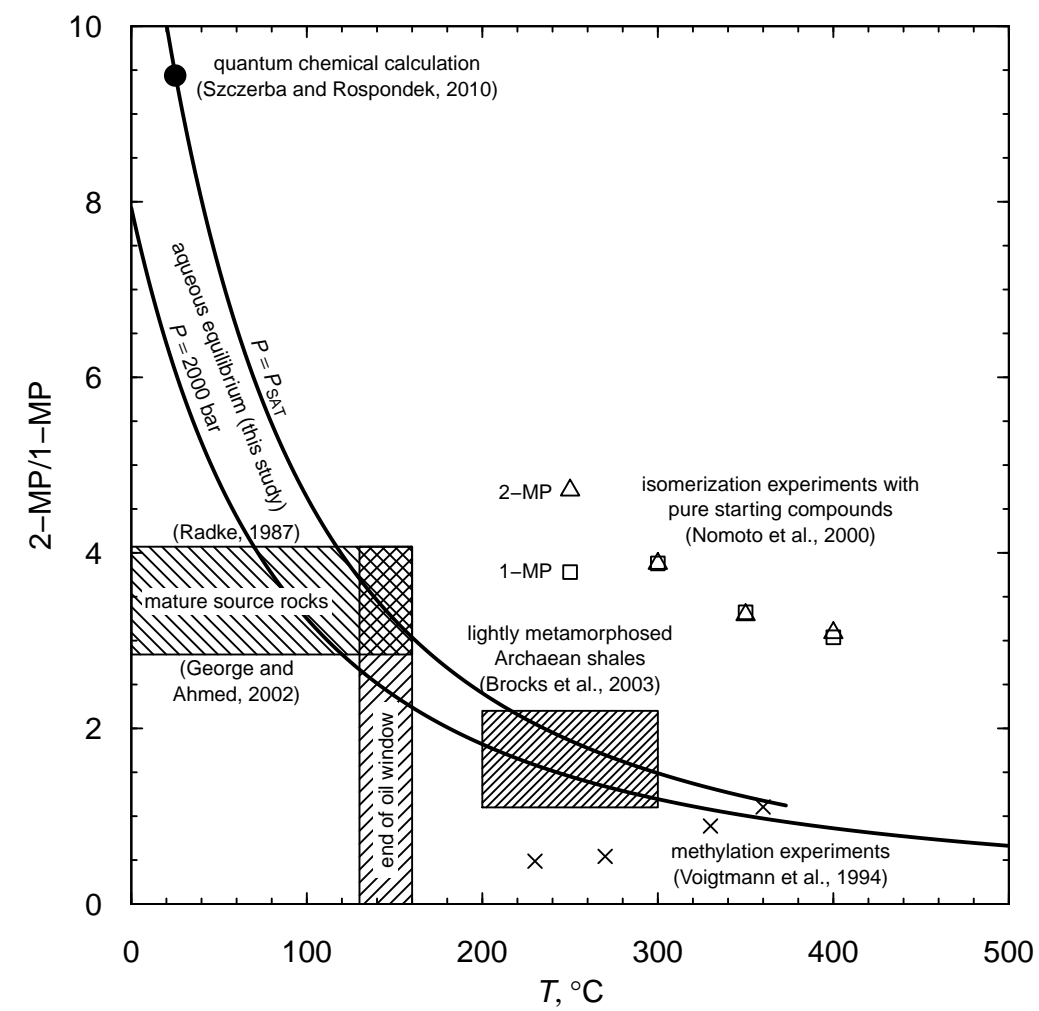

Figure 5: Comparison of metastable equilibrium values of MPR at $P=P_{\mathrm{SAT}}$ and $200 \mathrm{MPa}$ (2000 bar) (solid lines; this study) as a function of temperature with field-derived values (shaded boxes; George and Ahmed, 2002 and Radke, 1987 for a range of MPR in mature source rocks, and Brocks et al., 2003a for extractable hydrocarbons in late Archean shales of the Hamersley Group exposed to low-grade metamorphism), experimental values (open symbols; Nomoto et al., 2000 for experiments starting with pure 1-MP or 2-MP, as indicated, in the presence of a clay catalyst and Voigtmann et al., 1994 for methylation in hydrous pyrolysis experiments) and quantum chemical calculations (filled circle; Szczerba and Rospondek, 2010). The upper temperature limit of the oil window, made for comparison with the MPR in mature source rocks, is nominally taken to be between $130-160{ }^{\circ} \mathrm{C}$; see text for references. 


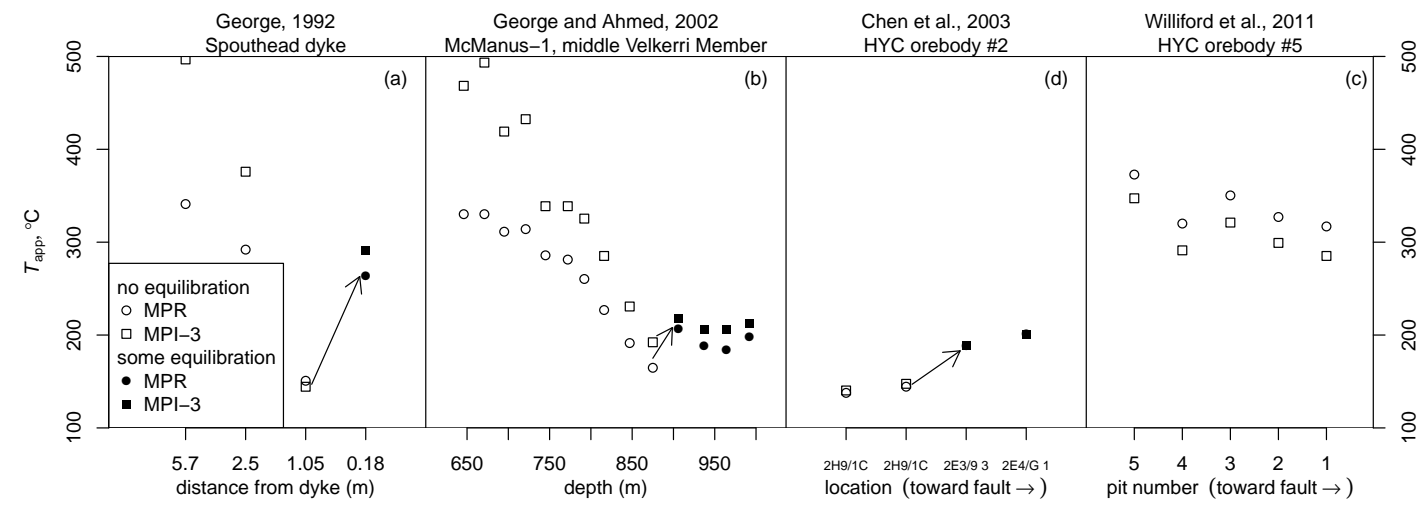

Figure 6: Plots of apparent temperature $\left(T_{\mathrm{app}}\right)$ for hypothetical assemblages of isomers of aqueous methylphenanthrene in metastable equilibrium that reproduce the values of MPR and MPI-3 reported in selected studies. Pressure is set to a constant value ( $P=25 \mathrm{MPa} ; 250 \mathrm{bar}$ ) above the critical pressure so that stability of the subcritical liquid is ensured; decreasing the pressure to $0.1 \mathrm{MPa}(1 \mathrm{bar})$ raises the $T_{\text {app }}$ by $\sim 5^{\circ} \mathrm{C}$. In each panel, the progression of sampling locations is arranged so that presumed higher temperatures are toward the right-hand side i.e. closer to the contact with the igneous intrusion as reported by George (1992) (a), deeper in the sediment column as reported by George and Ahmed (2002) (b), or closer to the source of hydrothermal fluids in the HYC ore deposit as reported by Chen et al. (2003) (c) and Williford et al. (2011) (d). Only in (b) is the scale of the $x$-axis linear with respect to depth; in the other plots, the gradations on the $x$-axis represent individual sampling locations. The total distance between sampling locations is approximately $800 \mathrm{~m}$ in the studies of both Chen et al. (2003) and Williford et al. (2011), but the samples in the respective studies are from different traverses in the mine. Open symbols indicate samples with values of MPR and MPI-3 that are interpreted in the present study to be primarily influenced by a kinetically controlled maturation process; arrows and filled symbols indicate an upward trend of $T_{\mathrm{app}}$ at high temperatures that is consistent with the onset of equilibration among the isomers (see Section 5.5). 


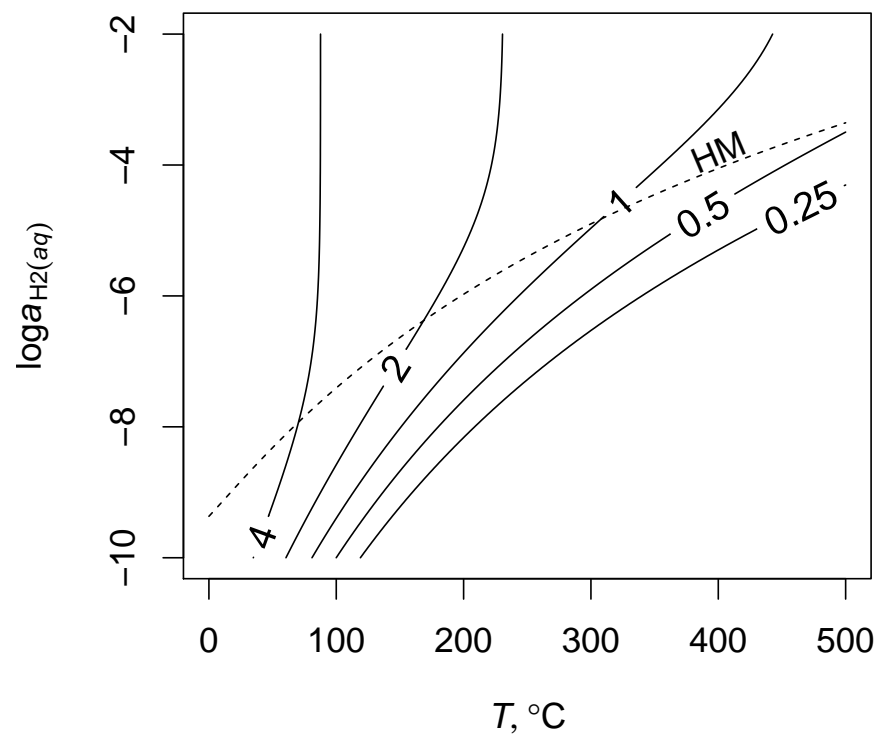

Figure 7: Metastable equilibrium values of MPI-1 (Eq. 3) as a function of $\log a_{\mathrm{H}_{2(a q)}}$ and temperature at $200 \mathrm{MPa}$ (2000 bar). The dashed line marked "HM" represents values of $\log a_{\mathrm{H}_{2(a q)}}$ computed for the hematite-magnetite buffer.
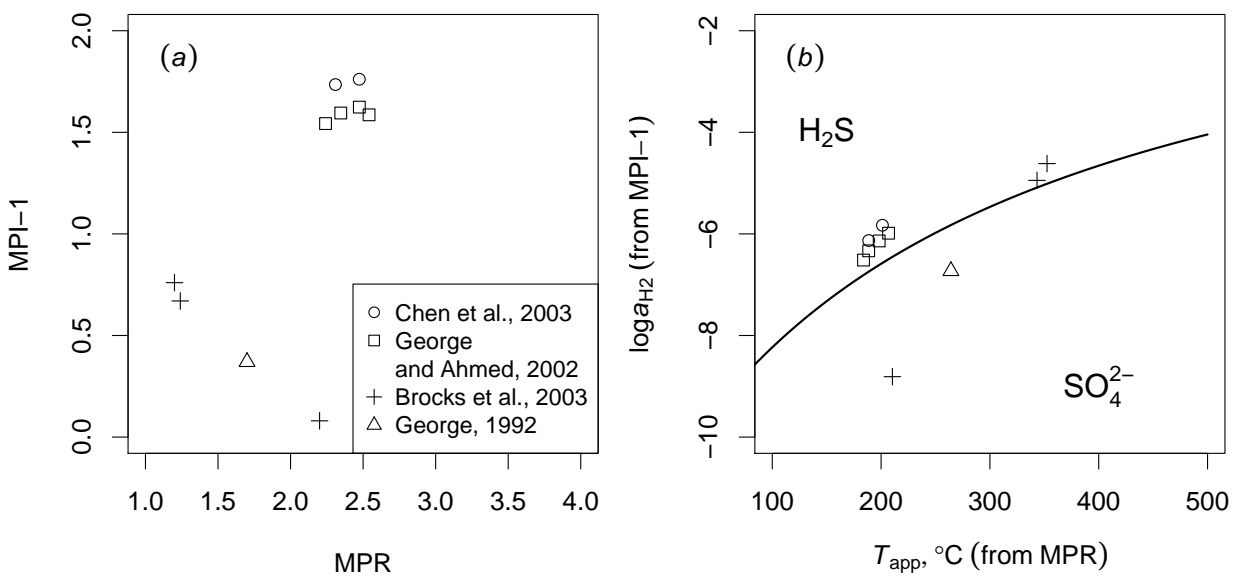

Figure 8: Values of (a) MPR (Eq. 1) and MPI-1 (Eq. 3) reported by various authors and (b) $\log a_{\mathrm{H}_{2(a q)}}$ and temperature calculated for a metastable equilibrium distribution of P and MP at 2000 bar (see Section 5.5 and Reaction 18). The line denotes conditions for equal activities of $\mathrm{SO}_{4}^{2-}$ and $\mathrm{H}_{2} \mathrm{~S}$ (Reaction 19) at $\mathrm{pH}$ of neutrality. Only data inferred to represent a metastable equilibrium distribution are included on these plots. 
Table 1: Standard molal thermodynamic properties of aqueous species generated in this study.

\begin{tabular}{|c|c|c|c|c|c|c|}
\hline & formula & $\Delta G_{f}^{\circ \mathbf{a}}$ & $\Delta H_{f}^{\circ \mathbf{a}}$ & $S_{P_{r}, T_{r}}^{\circ} \mathbf{b , d}$ & $C_{P}^{\circ \mathbf{b}, \mathbf{e}}$ & $V^{\circ \mathbf{c}, \mathbf{e}}$ \\
\hline phenanthrene & $\mathrm{C}_{14} \mathrm{H}_{10}$ & $300730^{\mathbf{f}}$ & $155570^{\mathrm{g}}$ & 246.9 & 447.3 & 161.6 \\
\hline 1-methylphenanthrene & $\mathrm{C}_{15} \mathrm{H}_{12}$ & $299310^{\mathbf{f}}$ & $128600^{\mathrm{g}}$ & 297.6 & 549.4 & 165.6 \\
\hline 2-methylphenanthrene & $\mathrm{C}_{15} \mathrm{H}_{12}$ & $293740^{\mathbf{h}}$ & $120150^{i}$ & 287.9 & 539.8 & 171.1 \\
\hline 3-methylphenanthrene & $\mathrm{C}_{15} \mathrm{H}_{12}$ & $294290^{\mathbf{h}}$ & $120610^{\mathbf{i}}$ & 287.7 & 539.8 & 171.1 \\
\hline 4-methylphenanthrene & $\mathrm{C}_{15} \mathrm{H}_{12}$ & $330230^{\mathbf{h}}$ & $152660^{i}$ & 274.6 & 569.2 & 177.6 \\
\hline 9-methylphenanthrene & $\mathrm{C}_{15} \mathrm{H}_{12}$ & $298090^{\text {h }}$ & $126760^{\mathbf{i}}$ & 295.5 & 549.4 & 165.6 \\
\hline
\end{tabular}

a. $\mathrm{J} \mathrm{mol}^{-1}$. b. $\mathrm{J} \mathrm{K}^{-1} \mathrm{~mol}^{-1}$. c. $\mathrm{cm}^{3} \mathrm{~mol}^{-1}$. d. Calculated by combining the values of $\Delta G_{f}^{\circ}$ and $\Delta H_{f}^{\circ}$ in this table with the entropies of the elements and $\Delta G^{\circ}=\Delta H^{\circ}-T \Delta S^{\circ}$. e. Calculated by combining the values of $C_{P}^{\circ}$ or $V^{\circ}$ of the crystalline compounds (Richard and Helgeson, 1998) with $\Delta C_{P, s o l}^{\circ}$ for $\mathrm{P}$ or 1-MP obtained in a least-squares fit using Eq. (9) of solubility data reported by May et al. (1983) or with $\Delta V_{\text {sol }}^{\circ}$ for P taken from Sawamura (2000) and $\Delta V_{\text {sol }}^{\circ}$ for all MPs calculated using Eq. (13). The $\Delta C_{P \text {.sol }}^{\circ}$ of 1-MP was used here for the other MPs, for which experimental data are lacking. The $C_{P}^{\circ}$ and $V^{\circ}$ of crystalline 3-MP and 9-MP, not given by Richard and Helgeson (1998), were taken to be equal to those of 2-MP and 1-MP, respectively. f. Calculated by combining the values of $\Delta G_{f}^{\circ}$ of the crystalline compounds (Richard and Helgeson, 1998) with $\Delta G_{\text {sol }}^{\circ}$ obtained in a least-squares fit using Eq. (9). g. Calculated by combining the value of $\Delta H_{f}^{\circ}$ of the crystalline compounds (Richard and Helgeson, 1998) with enthalpy of solution ( $\Delta H_{\text {sol }}^{\circ}$ ) calculated from $\Delta G_{\text {sol }}^{\circ}$ and $\Delta S_{\text {sol }}^{\circ}$ obtained in a least-squares fit using Eq. (9). h. Calculated by combining the value of $\Delta G_{f}^{\circ}$ of 1-MP in this table with the difference in $\Delta G$ between 1-MP and the other MPs given by Szczerba and Rospondek (2010). i. Calculated by combining the value of $\Delta H_{f}^{\circ}$ of 1-MP in this table with the difference in $\Delta H$ between 1-MP and the other MPs given by Szczerba and Rospondek (2010). 
Table 2: Experimental and calculated solubilities in water at $25^{\circ} \mathrm{C}$, in $\mathrm{mg} / \mathrm{L}$. Predicted values were obtained from EPISuite or calculated in this study.

\begin{tabular}{lrrc}
\hline & experimental & EPISuite $^{\mathbf{a}}$ & this study $^{\mathbf{b}}$ \\
\hline phenanthrene & $1.18^{\mathbf{c}}, 1.29^{\mathbf{d}}, 1.002^{\mathbf{e}}, 0.980^{\mathbf{f}}$ & 0.677 & 1.074 \\
1-methylphenanthrene & $0.269^{\mathbf{e}}, 0.270^{\mathbf{f}}$ & 0.1706 & 0.270 \\
2-methylphenanthrene & $0.28^{\mathbf{g}}$ & 0.2629 & 0.344 \\
3-methylphenanthrene & & 0.2629 & $0.275^{\mathbf{h}}$ \\
4-methylphenanthrene & & 0.1706 & 0.009 \\
9-methylphenanthrene & $0.446^{\mathbf{i}}$ & 0.2467 & $0.441^{\mathbf{h}}$ \\
\hline
\end{tabular}

a. Calculated using EPISuite (algorithm: WSKOW v1.41) (U.S. Environmental Protection Agency, 2011). b. Converted to units of $\mathrm{mg} / \mathrm{L}$ from the molal solubility calculated using Eq. (10), where $\Delta G_{\text {sol }}^{\circ}$ is the difference between $\Delta G_{f}^{\circ}$ at $25{ }^{\circ} \mathrm{C}$ of the crystalline compounds (Richard and Helgeson, 1998) and aqueous species (Table 1). c. Smoothed value at $25^{\circ} \mathrm{C}$ taken from Wauchope and Getzen (1972). d. Mackay and Shiu (1977). e. May et al. (1978). f. Taken from the fits to experimental solubilities as a function of temperature reported by May et al. (1983). g. Value listed by Isnard and Lambert (1989) from an unidentified source. h. Estimated using values of $\Delta G_{f}^{\circ}$ of crystalline 2-MP and 1-MP as substitutes for crystalline 3-MP and 9-MP, respectively. i. Taken to be 1/2.4 the solubility of P listed in the final column, based on a statement made by Rogoff (1962). 